\title{
Effects of cross-linking methods for polyethylene-based carbon fibers: review
}

\author{
Kwan-Woo Kim ${ }^{1,2}$, Hye-Min Lee ${ }^{1}$, Jeong-Hun An ${ }^{1}$, Byoung-Suhk Kim², \\ Byung-Gak Min ${ }^{3}$, Shin-Jae Kang ${ }^{1,4}$, Kay-Hyeok An ${ }^{1}$ and Byung-Joo Kim ${ }^{1, \$}$ \\ ${ }^{1}$ R\&D Division, Korea Institute of Carbon Convergence Technology, Jeonju 561-844, Korea \\ ${ }^{2}$ Department of Organic Materials and Fiber Engineering, Chonbuk National University, Jeonju 561-756, Korea \\ ${ }^{3}$ Department of Polymer Science and Engineering, Korea National University of Transportation, Chung-Ju 380-702, Korea \\ ${ }^{4}$ Department of Mechanical Design Engineering, Chonbuk National University, Jeonju 561-756, Korea
}

\section{Article Info}

Received 17 March 2015

Accepted 19 June 2015

*Corresponding Author

E-mail: kimbj2015@gmail.com

Tel: $+82-63-219-3720$

\section{Open Access}

DOI: http://dx.doi.org/

10.5714/CL.2015.16.3.147

This is an Open Access article distributed under the terms of the Creative Commons Attribution Non-Commercial License (http://creativecommons.org/licenses/ by-nc/3.0/) which permits unrestricted non-commercial use, distribution, and reproduction in any medium, provided the original work is properly cited.

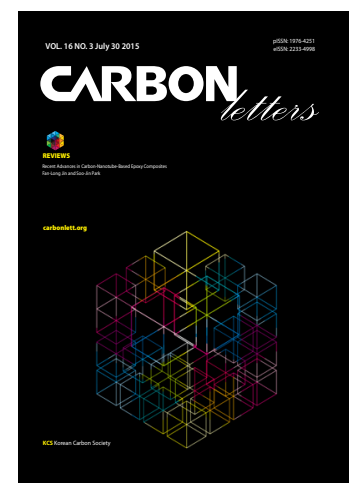

http://carbonlett.org

pISSN: 1976-4251

elSSN: 2233-4998

Copyright $\odot$ Korean Carbon Society

\begin{abstract}
In recent decades, there has been an increasing interest in the use of carbon fiber reinforced plastic (CFRP) in aerospace, renewable energy and other industries, due to its low weight and relatively good mechanical properties compared with traditional metals. However, due to the high cost of petroleum-based precursors and their associated processing costs, CF remains a specialty product and as such has been limited to use in high-end aerospace, sporting goods, automotive, and specialist industrial applications. The high cost of CF is a problem in various applications and the use of CFRP has been impeded by the high cost of CF in various applications. This paper presents an overview of research related to the fabrication of low cost CF using polyethylene (PE) control technology, and identifies areas requiring additional research and development. It critically reviews the results of cross-linked PE control technology studies, and the development of promising control technologies, including acid, peroxide, radiation and silane cross-linking methods.
\end{abstract}

Key words: polyethylene, cross-linked, low cost carbon fiber

\section{Introduction}

The carbon fiber (CF) industry has been growing continuously, with a focus on aerospace, military, and construction industries, as well as on medical, automobile, and sporting goods applications [1-4]. As a consequence of the increasing use of CFs in wind power systems and in the specialist industrial applications sector, the demand in the coming five years is expected to establish $\mathrm{CF}$ in the mass market. However, due to the high cost of their petroleum-based precursors and associated processing costs, $\mathrm{CF}$ remains fairly expensive [5-20].

The price of CFs is primarily driven by its manufacturing costs [20]. The total price of CF consists of $43 \%$ precursor costs, $46 \%$ processing costs, and $11 \%$ other costs. Consequently, in efforts to lower the price of $\mathrm{CF}$, research has mainly focused on the development of affordable precursors and processes [21,22]. Among all manufacturing processes, the manufacture of CFs is mainly based on polyacrylonitrile (PAN) [23], pitch [24], and rayon [25] based precursors.

Rayon-base precursors have proved to be inefficient, as the resulting fibers contain only about $20 \%$ carbon and have low strength and stiffness properties [26]. Although pitch-based CFs can be melt spun, the flow characteristics of mesophase pitch makes it extremely difficult to process. In addition, CFs derived from isotropic pitches have low tensile strengths, which do not meet the engineering requirements of the CF industry 
[27-29].

Among the precursors for the production of CFs, PAN is the predominant material, due to the excellent mechanical properties of PAN-based CFs [7]. However, the high cost of PAN precursors, which make up $46 \%$ of the CF manufacturing cost, limits its utilization in general performance grade applications in automotive parts [16].

To establish CFs in the mass market, the price of CF precursors has to be significantly reduced [10,20,23-25,30-40]. The lowest priced CF precursors primarily consist of polyethylene (PE) [41], lignin [33], and cellulose [42].

Cellulosic precursor fiber was first used by Thomas Edison in the 1880 s as the basis for his revolutionary electric lamp filament [43]. Much later, in 1959, the National Carbon Company introduced a carbon cloth from a rayon precursor and 2 years later carbon yarn became available [26,44]. In 1965, the Thornel range of CFs was announced, whose properties were improved by a post-carbonization treatment involving stretching at $2500^{\circ} \mathrm{C}$. This fiber had a tensile strength of $1.25 \mathrm{GPa}$ and a Young's modulus of $170 \mathrm{GPa}$ [45]. However, due to the cost of the hot stretching process and disadvantages in the yield and mechanical properties of the cellulose precursor [46] the production of these fibers lasted little more than 10 years [8]. Much of the focus of current work is on designing microstructure through control of precursor morphology and processing conditions [42]. Lignin is one of the most abundant substances in nature and is present in all fibrous plants, and as a byproduct of the pulp and paper industry.

Because lignin is a readily available and comparatively inexpensive polyaromatic macromolecule, it may fulfill many of the requirements needed as a precursor to CFs. Using lignin as a renewable feedstock for fine chemicals and materials has the potential to generate significant environmental and economic benefits necessary for the viability of the main processes. In spite of these large advantages, lignin has not yet been effectively utilized, and this presents environmental problems. Unfortunately, today's standard method for recovering lignin from papermill streams is not suitable for producing a high volume of lignin with properties suitable for fast and economically viable wet-spinning and eventual conversion to CFs with the quality requirements that industry demands [47]. In contrast, PE can easily be used to produce fibers at low cost, and has been applied as an industrial fiber. Also, PE has a high carbonization ratio in the carbonization process, and it can be melt spun. Because of these advantages, $\mathrm{PE}$ is promising for the manufacture of a low-cost CF $[41,48]$.

Among these materials, as a precursor for $\mathrm{CF}, \mathrm{PE}$ has the ability to reduce the cost of manufacturing by more than $50 \%$ compared to PAN [49]. Textile-grade PEs have been considered good candidates for affordable precursors because of their low cost [50]. PEs (high density PE [HDPE], low density PE [LDPE], linear low density PE [LLDPE]) can usually be crosslinked by four different methods, that is, by energy radiation [51], peroxide [52], silane coupling agents [53], and sulfonation [54] cross-linking.

In this paper, we review the various cross-linking methods used for manufacturing low priced CF from PE-based fibers. (a)

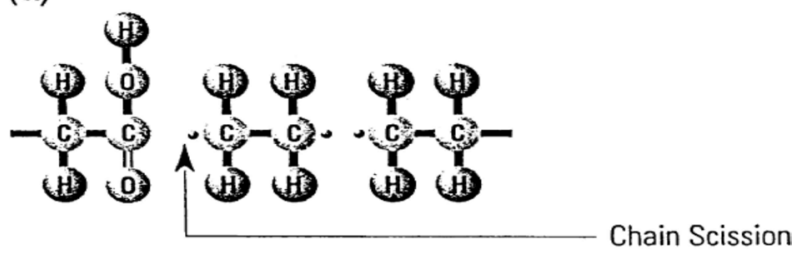

(b)

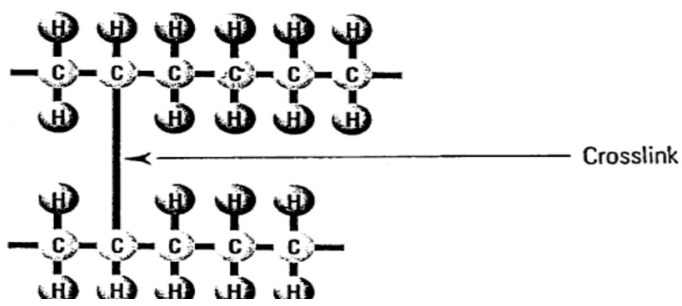

Fig. 1. (a) Chain scission in polyethylene (PE); (b) the cross-linking reaction, or formation of $\mathrm{C}-\mathrm{C}$ covalent bonds between adjacent molecular chains in PE [55].

\section{Processing Methods}

\subsection{Radiation}

When exposed to ionizing radiation, two structural changes occur in a polymer such as PE (Fig. 1). The first is chain scission (C-C breakage) of the 'taut' tie molecules (Fig. 1a). The second is a reaction of free radicals (produced by the breakage of the $\mathrm{C}$-H bonds) with each other to form crosslinks between adjacent molecule chains (Fig. 1b) [55].

\subsubsection{Gamma irradiation}

Alvarez and Perez [56] researched the crystallization behavior of PE cross-linked by radiation in different atmospheres, under non-isothermal conditions, using differential scanning calorimetry (DSC). The crystallization rate, the crystallization temperature and the crystallinity degree decreased with the radiation dose in nitrogen atmosphere, and with decreasing oxygen content at the same dose. On the other hand, the activation energy increased with the radiation dose and decreased with the oxygen content. These results are related to the increase in the degree of cross-linking, which restricts the crystallization process.

The full model was also used to build continuous cooling transformation (CCT) diagrams. The curves representing the relative degree of crystallinity at 0.3 were plotted as a function of time. Each point on these curves was obtained by the integration of the full model (nucleation and growth) at a given cooling rate. So, when the degree of crystallization curve is intercepted by a constant cooling rate curve, the obtained point represents the time necessary to reach a specific relative degree of crystallization under specific thermal conditions. From Fig. 2 it can be observed that the time necessary to reach the relative crystallinity degree of $30 \%$ increased with the radiation dose, indicating the dose increase had a retarding effect. On the other hand, the diagrams of samples irradi- 


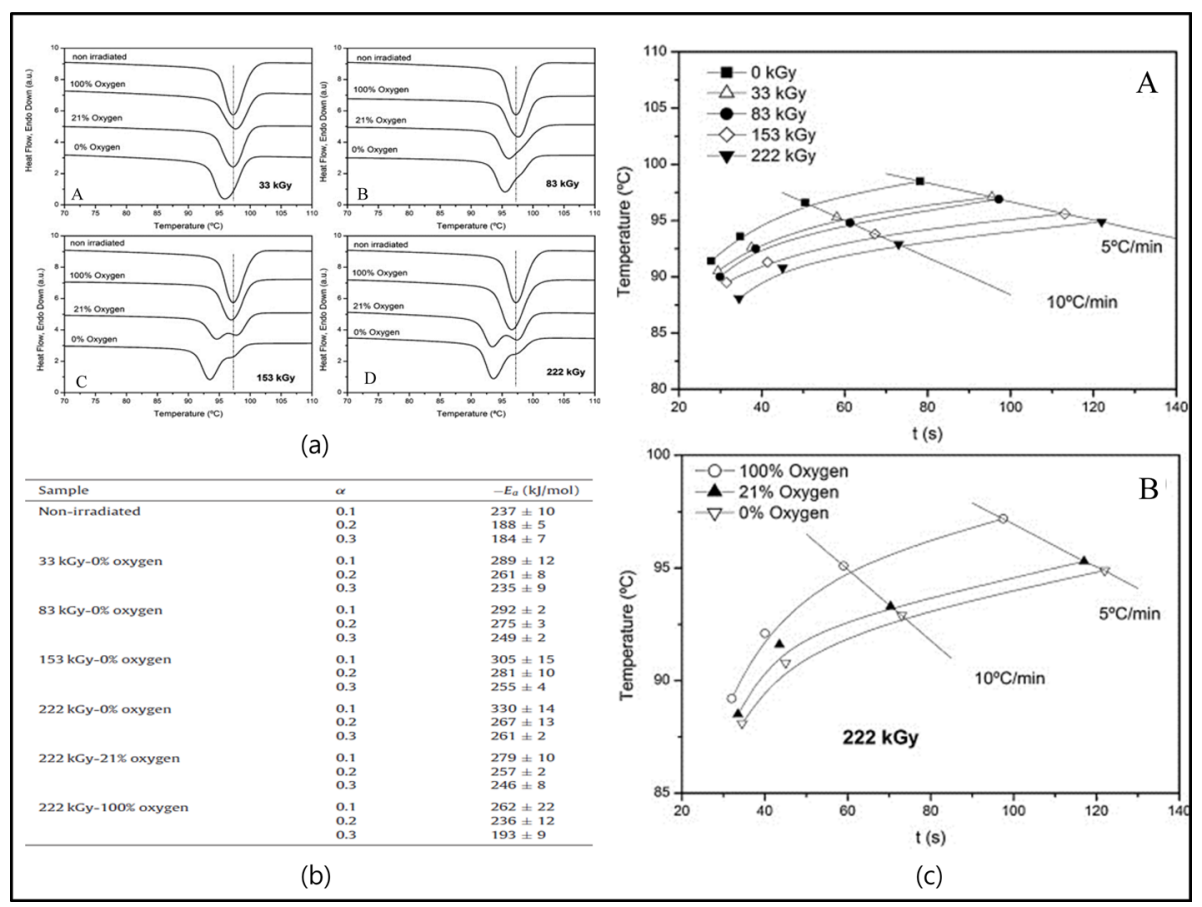

Fig. 2. Non-isothermal crystallization of gamma irradiated low density polyethylene (LDPE) in the presence of oxygen. Reprinted with permission from [56]: (a) non-isothermal crystallization curves obtained at a cooling rate of $10^{\circ} \mathrm{C} / \mathrm{min}$ of samples prepared with different oxygen concentrations $(\% \mathrm{v} / \mathrm{v})$, irradiated with $33 \mathrm{kGy}, 83 \mathrm{kGy}, 153 \mathrm{kGy}$, and $222 \mathrm{kGy}$; (b) activation energies of studied materials as a function of the relative degree of crystallinity; (c) CCT plots for A original and irradiated LDPE (nitrogen atmosphere) and B irradiated with $222 \mathrm{kGy}$ in different atmospheres.

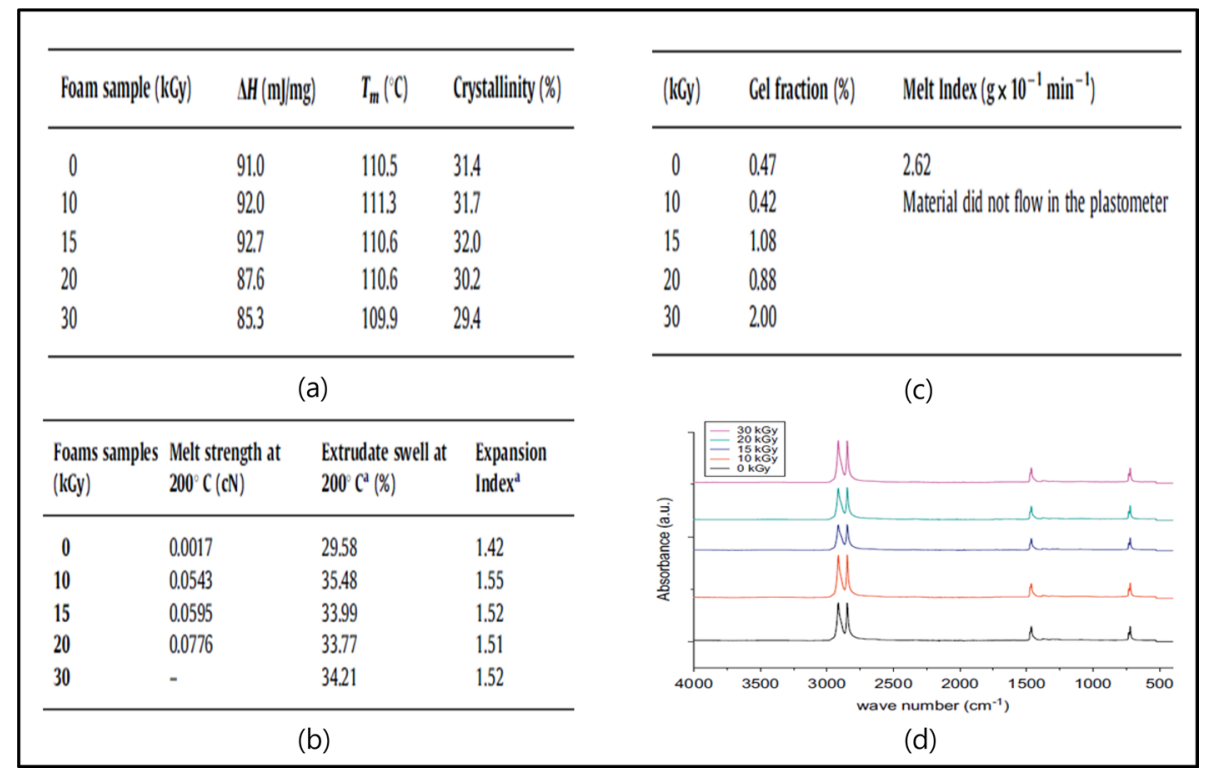

Fig. 3. Characteristics and properties of gamma irradiated cross-linked low density polyethylene foams. Reprinted with permission from [57]: (a) presents thermal behavior results obtained by each individual foam sample; (b) melt strength, extrudate swell and expansion index for 0-30 kGy foams samples; (c) gel fraction and melt flow index results in 0-30 kGy foams samples; (d) ATR spectra for 0-30 kGy foams samples (identification of carbonyl range: 1699, 1716 and $\left.1743 \mathrm{~cm}^{-1}\right)$.

ated in different atmospheres at $222 \mathrm{kGy}$ (Fig. 2) indicate that the retarding effect increased when the oxygen content decreased.

These diagrams allow the evolution of crystallinity degree to be determined for different processing conditions, which can be very useful for the design and optimization of processing steps, and clearly show a retarding effect with increasing irradiation dose and with decreasing oxygen content (Fig. 2). 


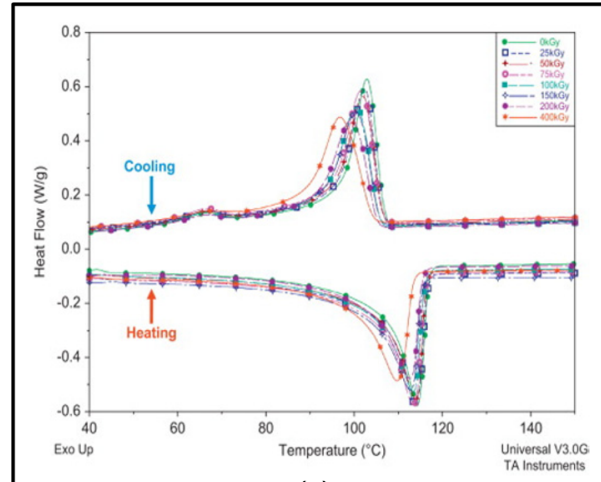

(a)

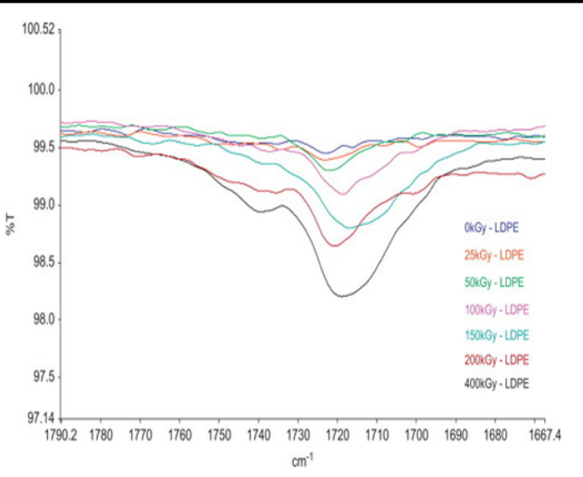

(b)

\begin{tabular}{llllllll}
\hline $\begin{array}{l}\text { Sample } \\
\text { dosage (kGy) }\end{array}$ & $H_{m}(\mathrm{~J} / \mathrm{g})$ & $\begin{array}{l}\text { Onset } \\
T_{m},{ }^{\circ} \mathrm{C}\end{array}$ & $\begin{array}{l}\text { Peak } \\
T_{m},{ }^{\circ} \mathrm{C}\end{array}$ & $\begin{array}{l}\text { Onset } \\
T_{\sigma}{ }^{\circ} \mathrm{C}\end{array}$ & $\begin{array}{l}\text { Peak } \\
T_{c},{ }^{\circ} \mathrm{C}\end{array}$ & \% crystallinity & $\begin{array}{l}\text { Crystallinity degree } \\
\text { variation (\%) }\end{array}$ \\
\hline 0 & 83.40 & 105.50 & 113.01 & 106.74 & 102.84 & 28.83 & 0.00 \\
25 & 81.38 & 103.90 & 113.12 & 106.39 & 102.40 & 28.13 & 2.42 \\
50 & 82.04 & 103.81 & 112.72 & 106.40 & 101.99 & 28.36 & 1.63 \\
75 & 82.43 & 102.53 & 112.59 & 106.09 & 101.63 & 28.49 & 1.16 \\
100 & 82.77 & 102.45 & 112.37 & 105.66 & 100.58 & 28.61 & 0.76 \\
150 & 76.59 & 100.95 & 111.67 & 105.52 & 100.41 & 26.47 & 8.17 \\
200 & 78.24 & 100.41 & 111.32 & 105.06 & 99.40 & 27.04 & 6.19 \\
400 & 79.08 & 97.87 & 109.24 & 103.99 & 96.94 & 27.33 & 5.18 \\
\hline \multicolumn{7}{c}{ (C) } \\
\hline 7
\end{tabular}

Fig. 4. Thermal and structural properties of energy electron beam irradiation on low density polyethylene (LDPE). Reprinted with permission from [58]: (a) MDSC thermograms of the second scan cycle for the nonirradiated and irradiated LDPE samples; (b) FTIR spectra for the non-irradiated and irradiated LDPE samples (carbonyl range); (c) melting temp erature $\left(T_{m}\right)$, crystallisation temperature $\left(T_{c}\right)$ and crystallinity of the LDPE, before and after electron beam irradiation.

Cardoso et al. [57] studied the results obtained for melt strength tests, which demonstrated that gamma radiation on $0,10,15,20$ and $30 \mathrm{kGy}$ foam samples, under ambient conditions, induced long chain branching, once carbonyl groups could not be detected via infrared analyses. The modified samples showed low values for gel fraction $(\leq 2 \%)$, and rheological tests confirmed the existence of branching and cross-linking, from $5 \mathrm{kGy}$ sample performance during melt strength evaluations. The low values obtained for crystallinity $-29.4 \%$ to $32.0 \%$ - showed a strict relation with rheological measurements, based on values for loss modulus (G") and Storage Modulus $\left(G^{\prime}\right): G^{\prime \prime}>G^{\prime}$, indicating the predominance of viscous behavior for samples tested. Difficult experiments to accomplish Melt Index evaluations in $>5 \mathrm{kGy}$ samples confirmed this observation. Even with low gel content $(<3 \%)$, the foam's processability could be maintained within a lower dose range modification: $\leq 15 \mathrm{kGy}$. Swelling experiments showed very low and similar results for $0,10,15$ and $20 \mathrm{kGy}$ foam samples, when immersed in xylene; the exception was the $30 \mathrm{kGy}$ sample. By repeating the swelling test with $\mathrm{xy}$ lene, immersions in hexane, toluene and cyclohexane were accomplished too, and the highest result with xylene was confirmed for the $30 \mathrm{kGy}$ sample, indicating that the swelling test should not be considered a parameter for an effective evaluation for radiation doses lower than $30 \mathrm{kGy}$ (Fig. 3).

2.1.2. Electron beam irradiation

Murray et al. [58] confirmed that the progressive decrease in $T_{m}$ with irradiation could be related to the preferential destruction of large crystals while the $T_{c}$ was also reduced due cross-linking, which prevented the macromolecular chains from crystallizing. Results from the Fourier transform infrared spectroscopy (FTIR) experimental technique strongly suggested that trans-vinylene double bond groups were formed, due to an increase in the intensity of the peak at $965 \mathrm{~cm}^{-1}$, which may be due to the presence of cross-linking. There was also strong evidence for the formation of oxidative products on the surface of the samples, which could be related to the reactions of the allyl radicals with oxygen molecules present in the air when the samples were exposed to air during and after the irradiation process. Therefore, it may be concluded that there are significant modifications in the thermal and structural properties of LDPE after irradiation (Fig. 4).

Using comparable irradiation doses, Khonakdar et al. [59] found that cross-linked LDPE samples which were more amorphous in nature, and which had highly active sites due to its branched structure, were more prone to cross-linking and hence had higher gel content as compared to cross-linked HDPE samples. The cross-link density and creep modulus calculated by rubber elasticity theory and hot set creep data, increased with increasing irradiation dose. As compared to HDPE, the LDPE had a higher cross-link density and consequently a lower $\mathrm{M}_{\mathrm{c}}$ value for any comparable irradiation dose, implying a higher network formation in the LDPE. The hot set measurement showed that the high concentration of cross-links (cross-link density) in the PE samples led to a longer resistance time and a lower elongation and a higher 


\begin{tabular}{|c|c|c|c|c|c|c|c|c|c|c|}
\hline \multirow[t]{2}{*}{$\begin{array}{l}\text { Absorbed } \\
\text { dose (kGy) }\end{array}$} & \multicolumn{2}{|c|}{ Gel content $(\%)$} & \multicolumn{2}{|c|}{$\begin{array}{l}\text { Tensile creep strain } \varepsilon \\
(\%)\end{array}$} & \multicolumn{2}{|c|}{$\begin{array}{l}\text { Creep modulus, }(\sigma / \varepsilon) \\
(\mathrm{MPa})\end{array}$} & \multicolumn{2}{|c|}{$\begin{array}{l}\text { Molecular weight } \\
\text { between cross-links, } \\
M_{\mathrm{c}}(\mathrm{g} / \mathrm{mol})\end{array}$} & \multicolumn{2}{|c|}{$\begin{array}{l}\text { Cross-link density, } v \\
(\mathrm{~mol} / \mathrm{L})\end{array}$} \\
\hline & LDPE & HDPE & LDPE & HDPE & LDPE & HDPE & LDPE & HDPE & LDPE & HDPE \\
\hline 100 & 63 & 37 & $\mathrm{a}$ & a & - & - & - & - & - & - \\
\hline 200 & 78 & 58 & 162.6 & 176.7 & 12.30 & 11.32 & 884.95 & 994.37 & 1.043 & 0.9594 \\
\hline 250 & 82 & 65 & 75.50 & 89.80 & 26.50 & 22.27 & 411.06 & 505.35 & 2.2454 & 1.8878 \\
\hline 300 & 85 & 68 & 51.30 & 63.60 & 38.99 & 31.45 & 279.30 & 357.90 & 3.3046 & 2.6655 \\
\hline \multicolumn{5}{|c|}{${ }^{\mathrm{a}}$ Failed after $5-8 \mathrm{~min}$} & \multicolumn{4}{|l|}{ (a) } & & \\
\hline \multirow{2}{*}{\multicolumn{2}{|c|}{ Irradiation dose (kGy) }} & \multicolumn{5}{|c|}{ LDPE } & \multicolumn{4}{|l|}{ HDPE } \\
\hline & & \multicolumn{2}{|c|}{$\Delta H_{\mathrm{m}}(\mathrm{J} / \mathrm{g})$} & $X_{\mathrm{c}}(\%)$ & \multicolumn{2}{|c|}{${ }^{I_{\mathrm{m}}} \quad\left({ }^{\circ} \mathrm{C}\right)^{{ }^{I_{\mathrm{c}}}}$} & $\Delta H_{\mathrm{m}}(\mathrm{J} / \mathrm{g})$ & $X_{\mathrm{c}}(\%)$ & \multicolumn{2}{|r|}{$\left({ }^{\circ} \mathrm{C}\right)$} \\
\hline 0 & & 146.3 & & 50.8 & 109.2 & 96.0 & 230.2 & 79.9 & 131.6 & 119.7 \\
\hline 50 & & 149.1 & & 51.7 & 108.3 & 95.4 & 220.0 & 76.4 & 132.2 & 118.4 \\
\hline 100 & & 144 & & 50.2 & 107.6 & 95.1 & 214.7 & 74.5 & 132.4 & 117.8 \\
\hline 150 & & 145.2 & & 50.4 & 107.5 & 93.9 & 227.3 & 78.9 & 132.4 & 117.6 \\
\hline 200 & & 140 & & 48.9 & 107.5 & 93.5 & 217.3 & 75.4 & 132.6 & 117.1 \\
\hline 250 & & 137. & & 47.9 & 107.6 & 92.7 & 223.2 & 77.5 & 132.7 & 116.2 \\
\hline
\end{tabular}

(b)

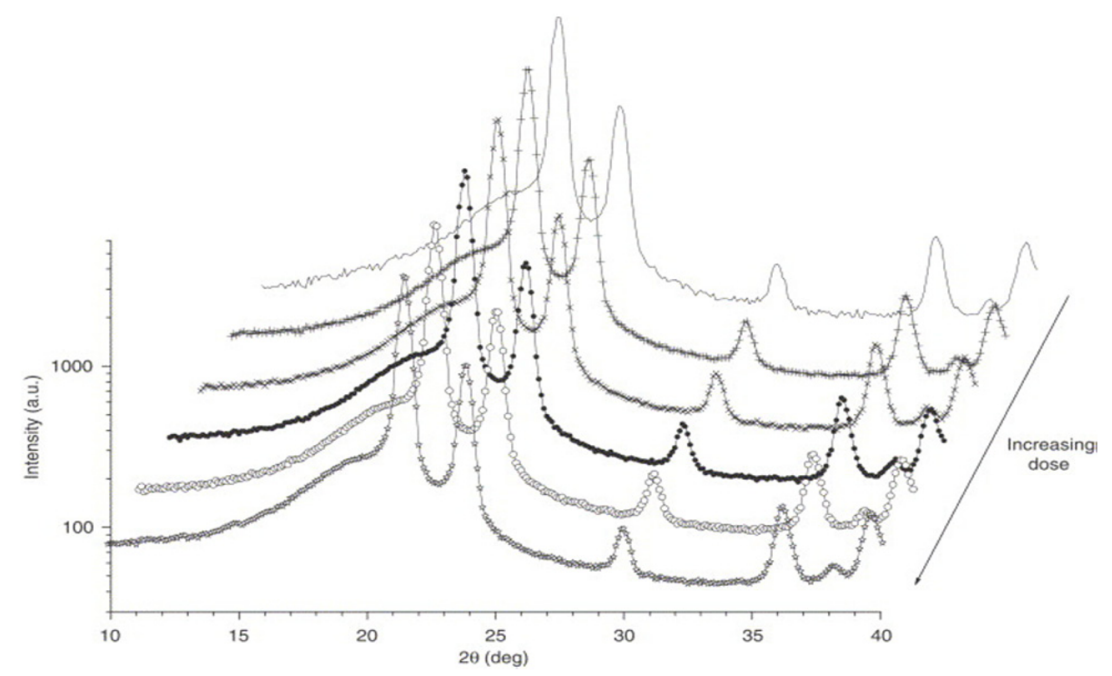

(c)

Fig. 5. Cross-link density and crystalline structure of electron-irradiation on low density polyethylene (LDPE) and high density PE (HDPE). Reprinted with permission from [59]: (a) gel content, cross-link density and hot set data for cross-linked LDPE and HDPE with different irradiation doses; (b) melting temperature $T_{m}$ heat of fusion $\Delta H_{m}$, degree of crystallinity $X_{c}$ of first heating of samples and crystallization temperature $T_{c}$ of irradiated LDPE and HDPE with different irradiation dose; (c) WAXS curves (shifrted 3D-plot) for HDPE irradiated with different dose rates (dose in kGy: - 0; - + - 50; - X-100; - - 150; -200 ; - 光 -250 ).

creep modulus in the hot set creep conditions before failure. Investigation of the thermal properties of the irradiated crosslinked PEs (XLPEs) at solid state showed that the melting point, heat of fusion $\left(\mathrm{H}_{\mathrm{m}}\right)$, and crystallinity $\left(\mathrm{X}_{\mathrm{c}}\right)$ were not changed significantly by increasing the irradiation doses. This was attributed to the immobilization of the generated free radicals in the crystalline region, with hindered chain mobility. Wide-angle X-ray scattering (WAXS) analysis also revealed no changes in crystalline structure and crystallite size of the irradiated PEs with increasing irradiation dose. The temperature of crystallization $\left(T_{c}\right)$ was reduced by increasing the irradiation dose. On cooling the molten samples in DSC, the samples showed various levels of crystallinity, whose effect was clearly evidenced in the second heating cycle by a decrease in melting temperature. The confined crystallization behavior of XLPE in the molten state was related to the decrease in the $\mathrm{M}_{\mathrm{c}}$. The length of chain segment motion needed for usual crystallization by the chain folding process was decreased, and hence the crystallization process was hindered (Fig. 5)

\subsubsection{Ion beam irradiation}

Turos et al. [60] reported that the deposition of high-energy density during ion beam bombardment caused irreversible 


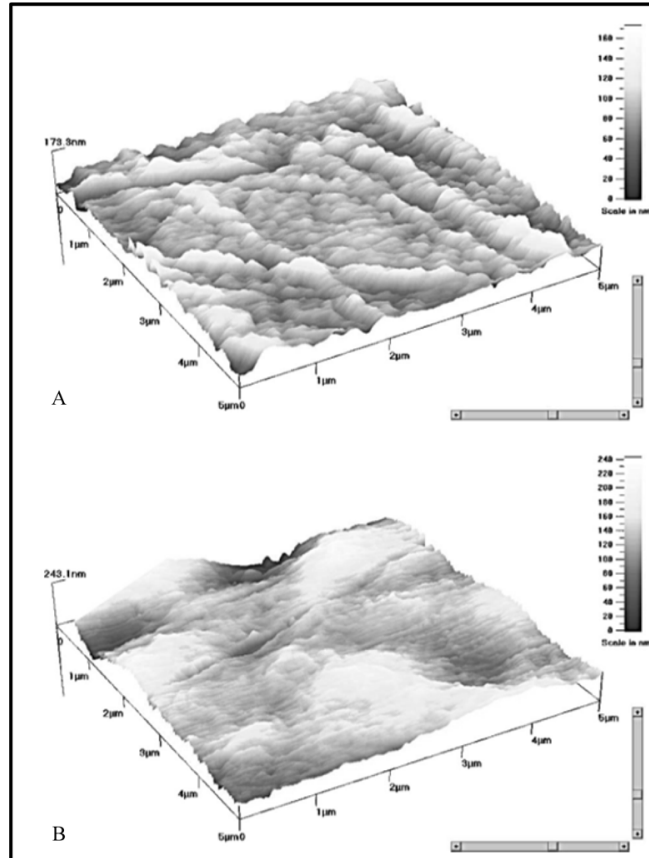

(a)

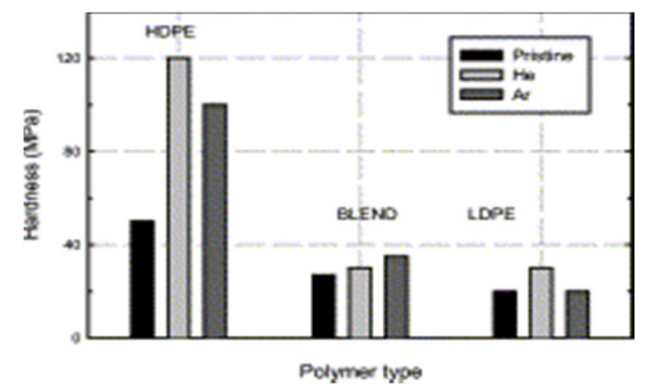

(d)

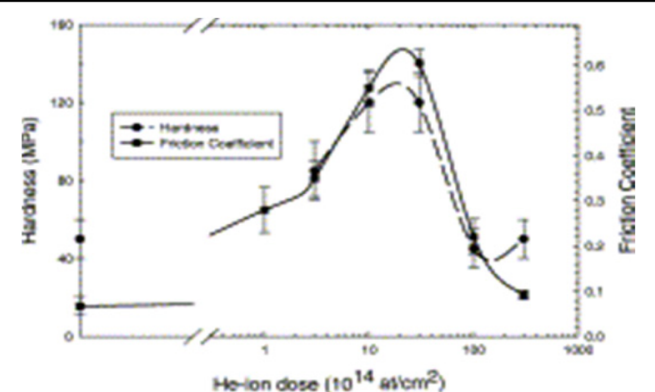

(b)

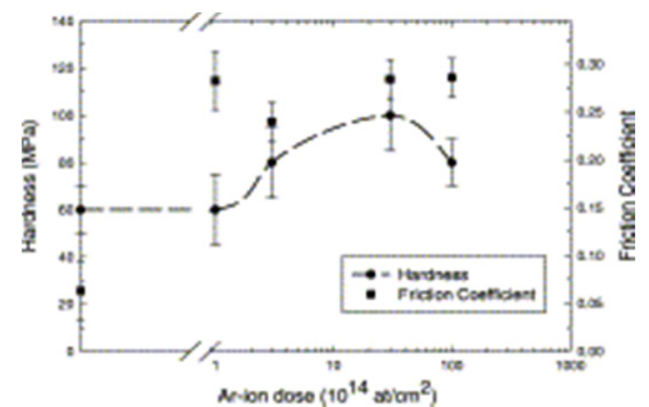

(c)

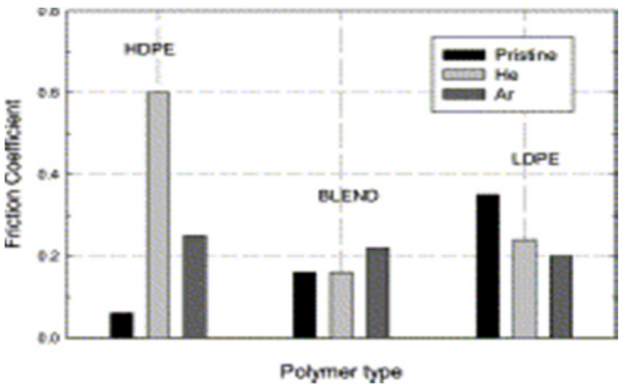

(e)

Fig. 6. Surface properties of ion beam modification of polyethylene. Reprinted with permission from [60]: (a) AFM micrographs of the HDPE surface of pristine sample $A$ and after the Ar-ion bombardment with a dose of $1 \times 10^{16} \mathrm{at} / \mathrm{cm}^{2} \mathrm{~B}$; (b) hardness and friction coefficient for HDPE as a function of the He-ion dose; (c) hardness and friction coefficient for HDPE as a function of the Ar-ion dose; (d) maximal values of hardness for different types of polyethylene prior and after ion bombardment; (e) maximal values of friction coefficient for different types of polyethylene prior and after ion bombardment.

changes in polymers [61]. Both cross-linking and scission occur simultaneously, but one of these two processes may prevail for a given polymer. Polymers having quaternary carbon atoms with large pendant groups were considered to be of the degrading type. In contrast, polymers with at least one hydrogen atom bound to each structural backbone carbon atom, such as PE, were of cross-linking type. Although structure plays an important role, it has been shown recently that the density of deposited energy may be a decisive factor as to whether scission or crosslinking occurs [62].

Cross-linking can occur only when two dangling bonds are located in neighboring chains. Diminishing the distance between such chains will facilitate their interaction. Hence, the probability of cross-linking will be much higher in HDPE than in LDPE. At low ion doses, the resulting microstructure consists of a poorly cross-linked network with some scissioned frag- ments. Upon continued irradiation, cross-linking proceeds and leads to the formation of a dense three dimensional network in the surface region. These structural transformations lead to higher molecular weight, and increased backbone structure rigidity. The improved mechanical integrity of such highly cross-linked surface regions is the reason for the increase in the friction coefficient and hardness of irradiated polymers. With an increasing ion dose, the exhaustion of cross-linkable sites occurs leading to the subsequent predominance of scission. These arguments explain the dose dependence of the HDPE tribological parameters shown in Fig. 6.

\subsection{Peroxide}

The cross-linking of PE with peroxide is based on a free radical mechanism. The free radicals generated by the thermal de- 


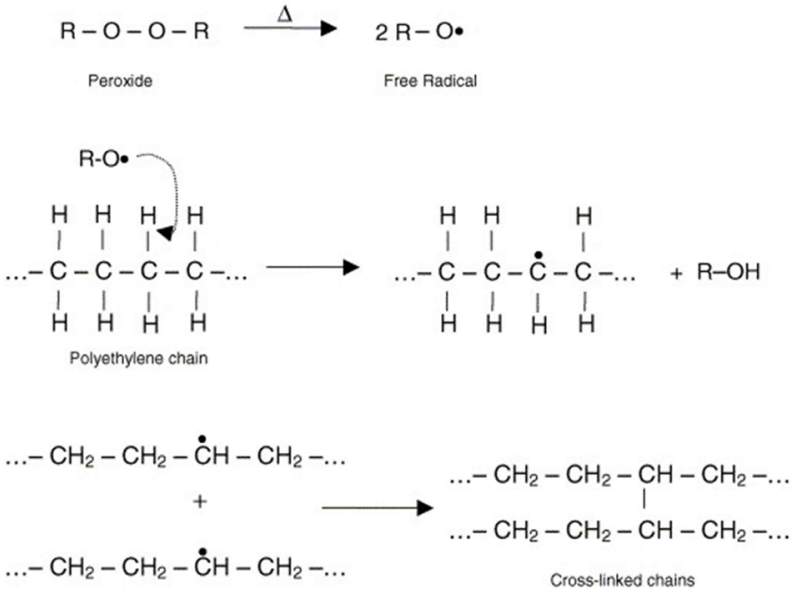

Fig. 7. Scheme of the mechanism of peroxide polyethylene crosslinking [71]. composition of peroxides can attack the molten PE free chains, and cross-linking of the polymer chains may occur. A general scheme for the cross-linking reaction of PE initiated by free radicals is quite simple, consisting of the formation of macro radicals and their subsequent recombination [63].

PE can be cross-linked by chemical initiators or by the use of $a b$, g or electron-beam irradiation sources. Within the literature on chemical methods, it is possible to find works where peroxides or silanes have been used for these purposes [64-70].

Cross-linking of PE can be initiated by a peroxide which decomposes as an effect of the temperature, as shown in the scheme in Fig. 7 [71]. The use of peroxides seems to present several advantages in comparison with other methods. For example, radiation cross-linking only modifies the properties on the polymer surface and the use of silane requires a twostep process, the grafting of the silane to the PE molecule and the condensation of silane groups, where the presence of

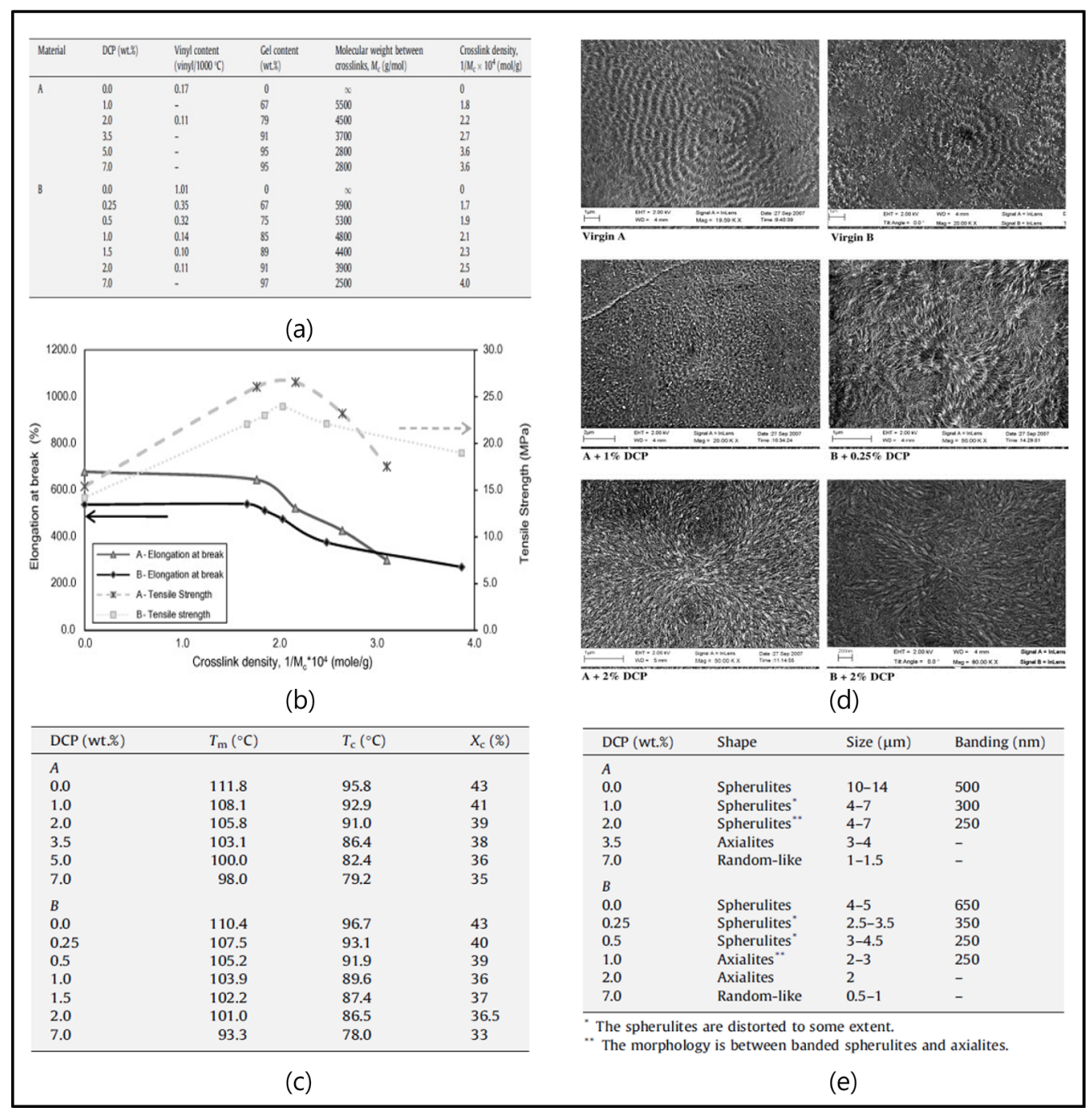

Fig. 8. Thermal and morphology properties of structural effects on cross-linked polyethylene. Reprinted with permission from [63]: (a) changes in vinyl content, gel content and crosslink density with DCP content; (b) elongation at break and ultimate tensile strength for material $A$ and $B ;$ (c) $T_{m}, T_{c}$ and $X_{c}$ as function of DCP content; (d) scanning electron micrographs on etched samples showing the change in spherulite size and structure and appearance after crosslinking with DCP; (e) morphology of materials $\mathrm{A}$ and $\mathrm{B}$ with increasing peroxide content. 


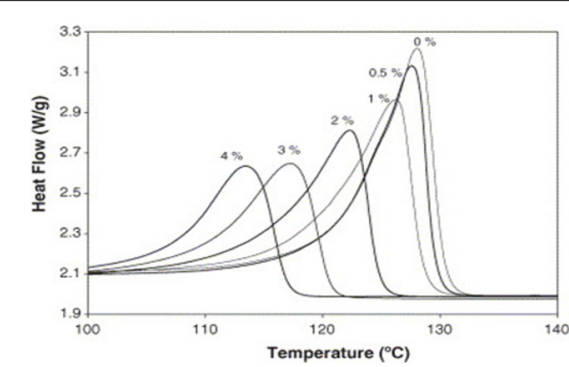

(a)

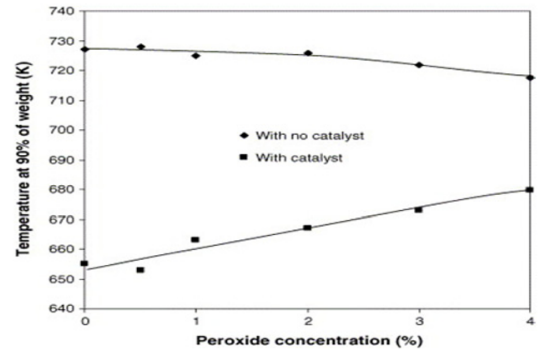

(b)

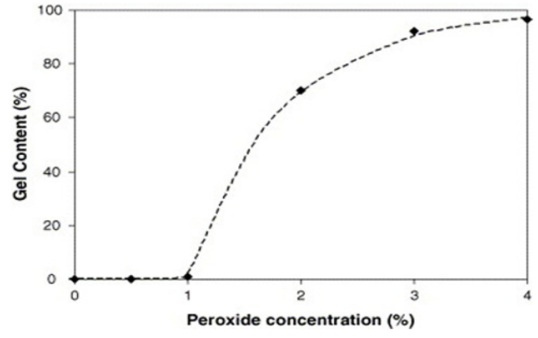

(c)

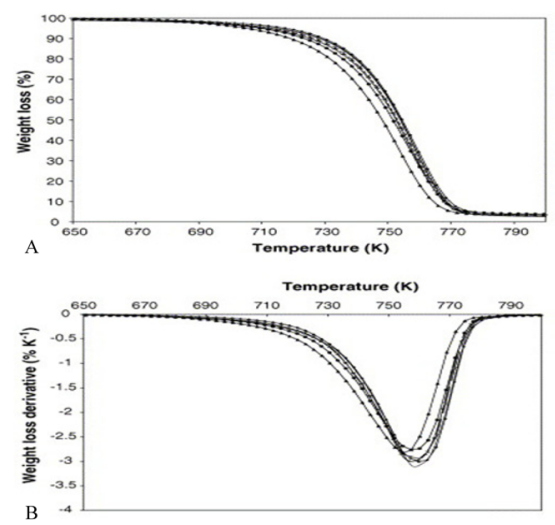

(d)

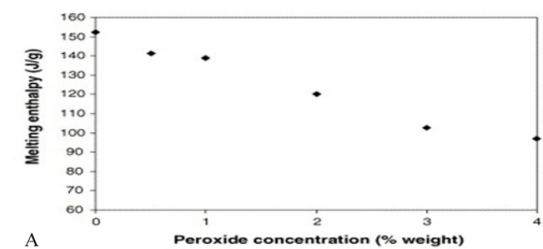

A

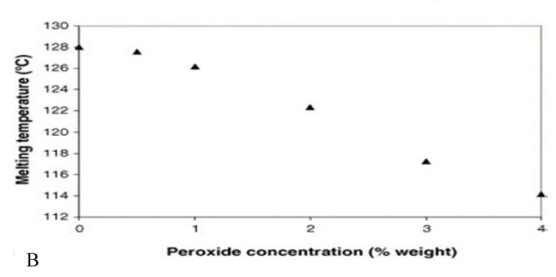

(e)

Fig. 9. Thermal and catalytic pyrolysis properties of cross-linked polyethylene. Reprinted with permission from [71]; (a) calorimetric curves of samples with different peroxide concentration; (b) temperature corresponding to $10 \%$ of weight loss for different samples with and without catalyst; (c) gel content measurements; (d) TGA A and DTG B curves for samples without catalyst: $(-) 0 \%$ peroxide, $(\$) 0.5 \%$ peroxide, $\left({ }^{*}\right) 1 \%$ peroxide, $(-) 2 \%$ peroxide, (-) 3\% peroxide, and (\$) 4\% peroxide; (e) melting enthalpy A and melting temperature B of crosslinked polyethylene samples with different peroxide concentration.

water (which has to diffuse through the polymer) is necessary $[64,69]$.

Nilsson et al. [63] investigated a reference LDPE (material A) and a LDPE with increased vinyl content (material B). The two LDPE materials were cross-linked mainly using combination cross-linking (A) or via a combination of reacted vinyl groups and combination cross-linking (B), with a resulting difference in the cross-linked network. A comparison of the materials at a low crosslink density, i.e. $\geq \mathrm{ca} 4500 \mathrm{~g} / \mathrm{mol}$, where the difference in crosslink methods was most evident, there was no obvious distinction between the materials. Both materials showed a decrease in $T_{m}, T_{c}$, and $X_{c}$ after cross-linking with an increasing amount of peroxide, due to the restraining effect of the incorporated crosslinks. Some smaller disparities in $\mathrm{T}_{\mathrm{m}}$ and $X_{c}$ could be noticed between the materials, possibly due to the difference in crosslink structure. Mechanical testing, stepwise increasing strain test (SIST) and scanning electron microscopy (SEM) measurements supported the results obtained from the DSC studies. A change from fairly well developed spherulites to nonbanded axialites occured at approximately the same crosslink density for both materials A and B. Hence, the morphological structure was similar irrespective of the different crosslink mechanisms, at a certain crosslink density. This indicates that the type of crosslink does not influence the results at the crosslink densities studied. However, the size and perfection of the supermolecular structures differed between the two materials, with material $\mathrm{B}$ having smaller and less perfect structures than material A (Fig. 8).

Research results obtained Marcilla et al. [71] revealed that the utilization of a catalyst enhances differences among samples with different degrees of cross-linking, in contrast to the case of samples decomposed in the absence of catalyst, where very slight differences could be observed. The changes undergone by cross-linking, even at very low gel content, were markedly reflected in the thermogravimetric behaviour. In this study, catalytic pyrolysis was proved to be an alternative technique to monitor cross-linking, which allows the comparison of samples with different degrees of cross-linking 


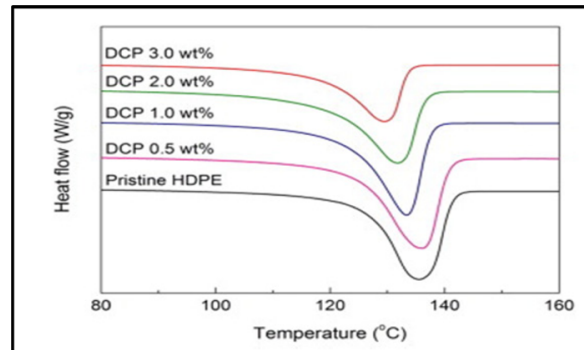

(a)
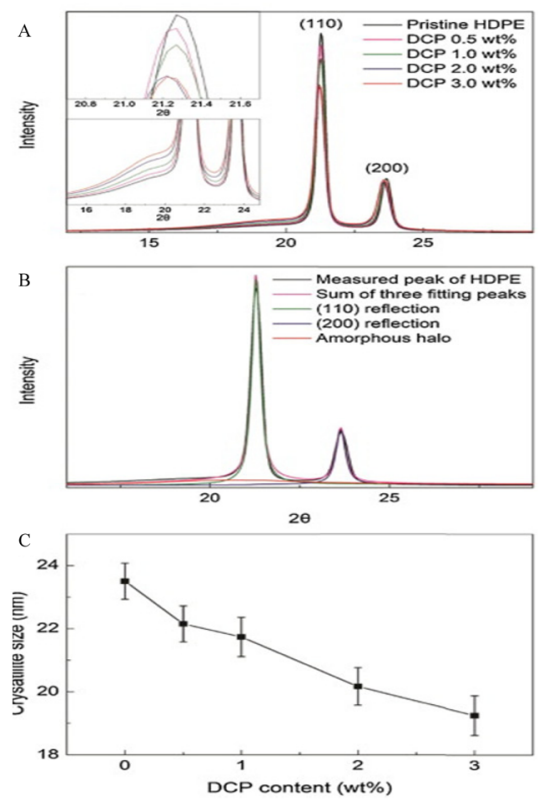

(b)

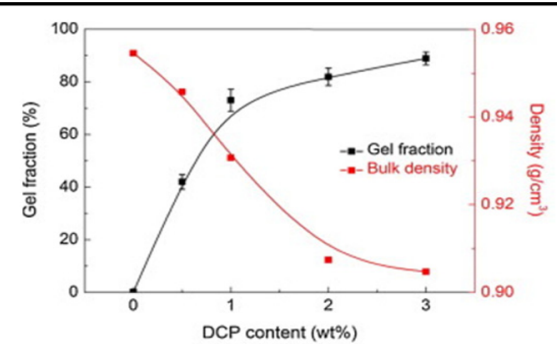

(c)
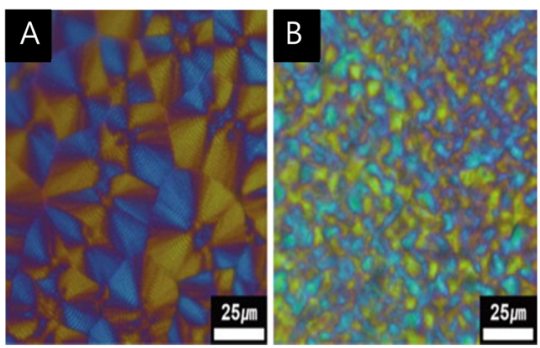

(d)

\begin{tabular}{|c|c|c|c|c|}
\hline $\begin{array}{l}\text { DCP } \\
\text { Content }\end{array}$ & $\begin{array}{l}\text { Themal } \\
\text { oifusivity } \\
\left(\mathrm{mm}^{2} \mathrm{~s}^{\mathrm{s}}\right)\end{array}$ & $\begin{array}{c}\text { Specisc hest } \\
\text { (JgKK) }\end{array}$ & $\begin{array}{l}\text { Densiry } \\
\left(\mathrm{g} \mathrm{cm}^{\prime}\right)\end{array}$ & $\begin{array}{l}\text { Themal } \\
\text { consostiviyy } \\
(\mathrm{N} / \mathrm{mK})\end{array}$ \\
\hline 0 & 0.306 & 1.789 & 0.9545 & 0.5225 \\
\hline 0.5 & 0.249 & 1.809 & 0.9457 & 0.4280 \\
\hline 1 & 0.231 & 1.842 & 0.9307 & 0.3960 \\
\hline 2 & 0.217 & 1.855 & 0.9074 & 0.3653 \\
\hline 3 & 0.204 & 19.37 & 0.9047 & 0.3574 \\
\hline
\end{tabular}

(e)

Fig. 10. Thermal conduction behaviors of chemically cross-linked high-density polyethylenes (HDPEs). Reprinted with permission from [72]; (a) DSC thermographs of pristine and crosslinked HDPEs via a heating scan; (b) A synchrotron WAXS patterns of HDPE and crosslinked HDPEs. Top and bottom insets show high magnification of (110) diffraction and amorphous halo B resolved peaks of HDPE, and C crystallite size of HDPE and crosslinked HDPEs; (c) gel contents and bulk densities of the pristine and crosslinked HDPEs with various DCP contents; (d) polarized optical micrographs of A HDPE and B crosslinked HDPE with DCP 3.0 wt.\%; (e) characteristics of the pristine and crosslinked HDPEs with various DCP contents including thermal diffusivity, density and specific heat data.

by a quicker procedure than solvent extraction. Furthermore, this method is able to reflect molecular changes associated to cross-linking not observable by other techniques, as determined by gel content. This procedure could be of particular applicability in amorphous polymers, where changes associated with cross-linking cannot be monitored by calorimetric curves (Fig. 9).

Yu et al. [72] studied the effect of chemical cross-linking on the thermal conductivity of HDPE in order to investigate the influence of chemical cross-linking on the thermal conductivity. The gel content, density, spherulite size, crystallite size and crystallinity were strongly affected by the content of the dicumyl peroxide (DCP) cross-linking agent. As the DCP content increased, the gel content increased while the density, spherulite size, crystallite size and crystallinity rapidly decreased. The thermal conductivity synchronously decreased with a decrease in the crystallinity (Fig. 10).

Wu et al. [73] demonstrated that solid state mechanochemi- cal milling using a pan-mill equipment is a good method to recycle XLPE by partial de-cross-linking. In order to investigate the effect of the milling process on the crystallization kinetics of XLPE, three different kinetic models, the Avrami, the Ozawa and the Mo, were applied to systematically study the non-isothermal crystallization kinetics of XLPE, de-XLPE and LDPE based on the DSC technique. All three models were found to describe the experimental data very well.

The parameters $Z_{c}$ and $t_{1 / 2}$ derived from the modified Avrami method suggested that de-XLPE had a faster crystallization rate than XLPE due to higher chain mobility, which resulted from partial de-cross-linking. $\mathrm{K}(\mathrm{T})$ from the Ozawa method revealed a tendency that fit well with the results of the Avrami method. In addition, the Ozawa method was found to be a satisfactory description of the non-isothermal crystallization process of LDPE, while its secondary crystallization was not obvious and could be neglected. From the Mo method, the value of $F(T)$ of de- 


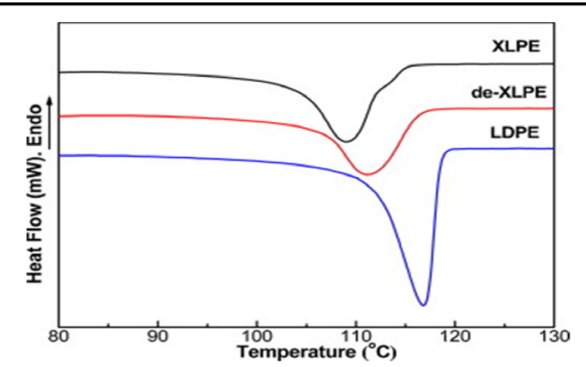

(a)

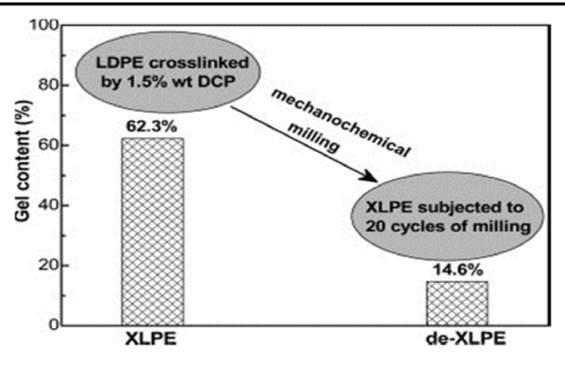

(b)

\begin{tabular}{lcccccc}
\hline Sample & Cooling rate $\Phi(\mathrm{K} / \mathrm{min})$ & $T_{\mathrm{o}}\left({ }^{\circ} \mathrm{C}\right)$ & $T_{\mathrm{p}}\left({ }^{\circ} \mathrm{C}\right)$ & $\Delta H_{\mathrm{c}}(\mathrm{J} / \mathrm{g})$ & $X_{\mathrm{c}}\left(\mathrm{F}^{\circ}\right)$ & $t_{1 / 2}{ }^{2}(\mathrm{~min})$ \\
\hline XLPE & 2.5 & 112.8 & 109.1 & 100.0 & 34.5 & 1.60 \\
& 5 & 112.0 & 106.8 & 97.3 & 33.6 & 1.13 \\
& 10 & 110.8 & 103.0 & 91.7 & 31.6 & 0.91 \\
de-XLPE & 20 & 109.0 & 97.1 & 85.8 & 29.6 & 0.61 \\
& 2.5 & 116.2 & 111.2 & 135.2 & 46.6 & 1.94 \\
& 5 & 115.2 & 109.5 & 132.7 & 45.8 & 1.09 \\
& 10 & 114.1 & 107.8 & 128.2 & 44.2 & 0.70 \\
LDPE & 20 & 112.3 & 104.5 & 112.7 & 38.9 & 0.43 \\
& 2.5 & 118.7 & 116.6 & 194.3 & 67.0 & 1.04 \\
& 5 & 118.0 & 114.7 & 192.9 & 66.5 & 0.78 \\
& 10 & 117.0 & 112.0 & 189.5 & 65.4 & 0.62 \\
& 20 & 114.9 & 108.2 & 168.9 & 58.3 & 0.41 \\
\hline
\end{tabular}

(c)

\begin{tabular}{|c|c|c|c|c|c|c|c|c|c|}
\hline \multirow[t]{2}{*}{ Temperature $\left({ }^{\circ} \mathrm{C}\right)$} & \multicolumn{3}{|c|}{ XLPE } & \multicolumn{3}{|c|}{ de-XLPE } & \multicolumn{3}{|l|}{ LDPE } \\
\hline & $\mathrm{m}$ & $K(T)$ & $R^{2}$ & $m$ & $K(T)$ & $R^{2}$ & $m$ & $K(T)$ & $R^{2}$ \\
\hline 107 & 1.75 & 8.76 & 1.00 & 1.38 & 16.78 & 0.99 & - & - & - \\
\hline 108 & 1.89 & 6.30 & 1.00 & 1.42 & 12.43 & 0.99 & - & - & - \\
\hline 109 & 2.01 & 3.82 & 1.00 & 1.53 & 9.49 & 0.98 & 1.60 & 47.47 & 0.99 \\
\hline 110 & 2.13 & 1.75 & 0.98 & 1.70 & 8.08 & 0.95 & 1.67 & 40.85 & 1.00 \\
\hline 111 & - & - & - & 1.65 & 7.17 & 0.99 & 1.71 & 33.12 & 1.00 \\
\hline 112 & - & - & - & 1.73 & 2.59 & 0.98 & 1.80 & 27.11 & 1.00 \\
\hline
\end{tabular}

(d)

Fig. 11. Non-isothermal crystallization kinetics of peroxide-cross-linked polyethylene (XLPE): effect of solid state mechanochemical milling. Reprinted with permission from [73]; (a) DSC thermograms of non-isothermal crystallization for XLPE A, de-XLPE B, and LDPE C at the cooling rate of $2.5^{\circ} \mathrm{C} / \mathrm{min}$; (b) effect of mechanochemical milling on the gel content of XLPE; (c) characteristic data of nonisothermal crystallization exotherms for XLPE, de-XLPE, and LDPE at different cooling rates; (d) non-isothermal crystallization kinetic parameters based on the Ozawa method.

XLPE was found to be lower than that of XLPE, which also indicated that the de-cross-linking effect of mechanochemical milling could accelerate the overall crystallization process (Fig. 11).

\subsection{Silane}

Silane coupling agents are silicon-based organic chemicals that contain two types of substituent (inorganic and organic) in the same molecule $[74,75]$.

Their typical general formula is $(\mathrm{X})_{3} \mathrm{Si}-\mathrm{Y}$, where $\mathrm{X}$ represents a hydrolyzable group such as ethoxy or methoxy, $\mathrm{Y}$ is a functional organic group (amino, methoxy, acetoxy, epoxy, etc.) that reacts with water to form silanol $(\mathrm{Si}-\mathrm{OH})$. They include more than 90 percent of the plastic coupling agents market and are also used in the cross-linking of polyolefins and some other polymers [76-78].

Since the silane groups are polar they provide compatibility in PE based blends, where the PE is non-polar in nature [79]. Vinyl alkoxy silanes (e.g., vinylmethyldimethoxysilane, vinyltriethoxysilane [VTES], vinyltrimethoxysilane) are suitable compounds for these kinds of reactions due to their double
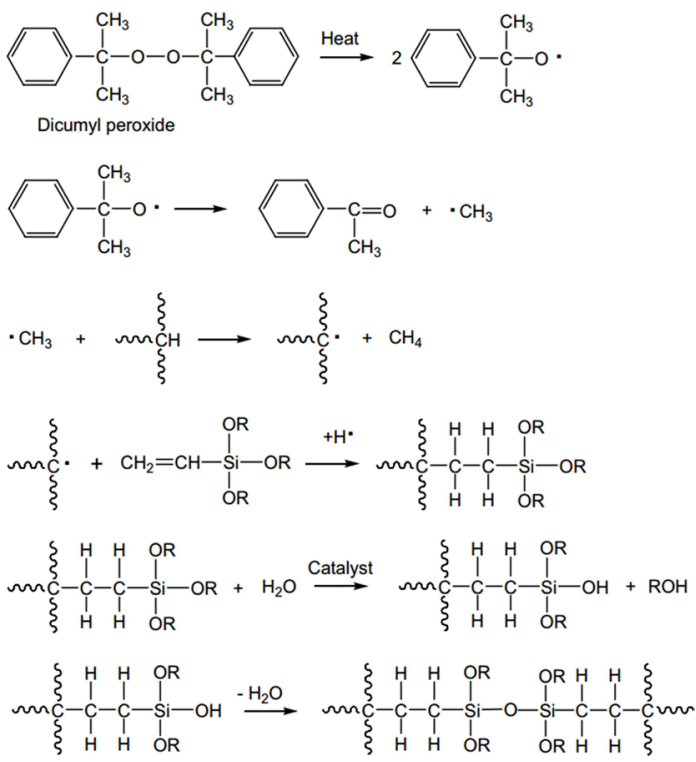

Fig. 12. Principal reactions involved in silane cross-linking of polyethylene [82]. 


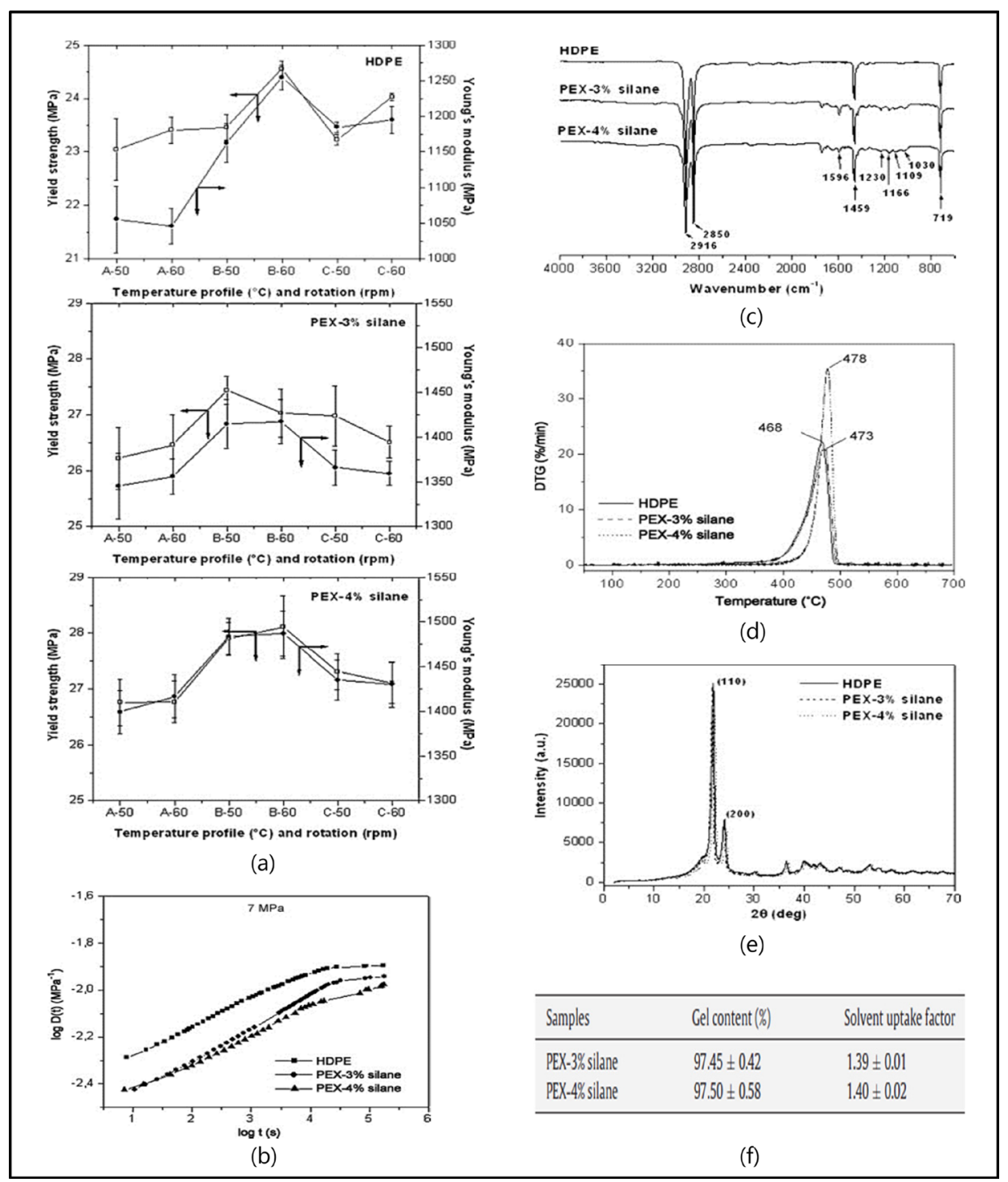

Fig. 13. Characterization and mechanical properties of cross-linked high density polyethylene (HDPE) by silane. Reprinted with permission from [83]: (a) yield strength and Young's modulus as a function of processing conditions of HDPE, PEX - $3 \%$ silane, and PEX - $4 \%$ silane; (b) yield strength and Young's modulus as a function of processing conditions of HDPE; (c) FTIR spectra of HDPE and PEXs crosslinked with $3 \%$ and $4 \%$ silane; (d) DTG curves of HDPE and PEX with 3\% and 4\% silane; (e) X-ray diffractograms of samples of HDPE and PEX with 3\% and 4\% silane; (f) gel content and solvent uptake factor values of the extraction carried out with trichloroethylene for crosslinked samples at crosslinking time of $90 \mathrm{~min}$.

bonds and ability to promote rapid cross-linking. Vinyltrimethoxysilane is the most common silane used in the manufacturing of silane cross-linkable PE [80].

Silane-grafting by water-cross-linking method consists of at least two stages that also proceed consecutively [81]. In the first stage, a proper silane (vinylalkoxysilane) is grafted via its vinyl groups on PE through a peroxide initiated free radical reaction; it should be noted that during the grafting reactions, new PE radicals are formed (Fig. 12) and the required amount of peroxide is relatively low. In the second stage, the resultant copolymer is crosslinked via exposure to hot water or steam with the aid of a catalyst. Moisture leads to hydrolysis of the alkoxy groups of silane and thereafter, these hydroxyl groups condense to form stable siloxane linkages (the crosslinks). Fig. 12 illustrates the reaction mechanism during peroxide induced melt grafting of vinyl silane onto PE, followed by the hydrolysis and condensation step during the silane crosslinking reaction [82].

Oliveira and Costa [83] found that, after optimization of the cross-linked PE (PEX) process conditions by extrusion, the process speed did not significantly affect tensile mechanical properties such as modulus of elasticity and yield strength, although an increasing trend was observed for materials processed at temperature range $B$. This trend was greater when combined with $60 \mathrm{rpm}$ speed, which made it possible to define the optimum PEX extrusion condition. Infrared analysis allowed the PEXs development to be confirmed, and the 


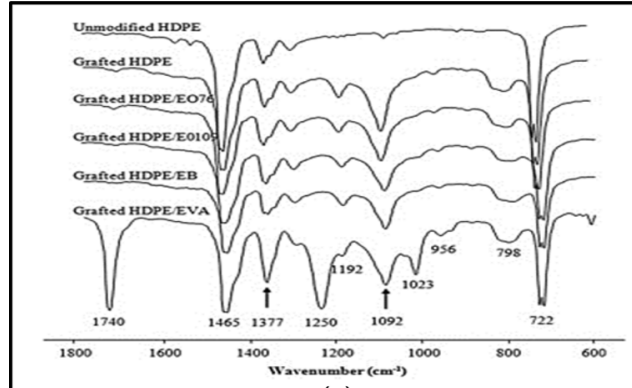

(a)

\begin{tabular}{ll}
\hline $\begin{array}{l}\text { Peak } \\
\left(\mathrm{cm}^{-1}\right)\end{array}$ & Functional Group \\
\hline 1740 & $>\mathrm{C}=\mathrm{O}$ stretching (ester carbonyl group) \\
1465 & $\mathrm{CH}$ bending vibration (methylene group) \\
1377 & $\mathrm{CH}$ bending vibration (methylene group) \\
1250 & $\mathrm{C}-\mathrm{O}$ stretching (ester and acid group) \\
1192 & $\mathrm{Si}-\mathrm{O}-\mathrm{C}$ (methoxysilane group) \\
1092 & $\mathrm{Si}-\mathrm{O}-\mathrm{C}$ (methoxysilane group) \\
1023 & $=\mathrm{C}-\mathrm{O}-\mathrm{C}$ stretching (ester and acid group) \\
956 & $\mathrm{C}-\mathrm{H}$ deformation (acetate group) \\
798 & $\mathrm{Si}-\mathrm{O}-\mathrm{C}$ (methoxysilane group) \\
722 & $\mathrm{CH}_{2}$ rocking vibration (branch point of PE mainly) \\
\hline
\end{tabular}

(b)

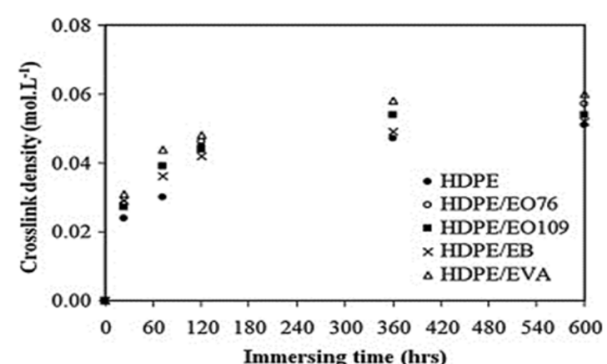

(c)

\begin{tabular}{|c|c|c|c|c|c|}
\hline \multirow[t]{2}{*}{ Materials } & $\underline{T_{m}\left({ }^{\circ} \mathrm{C}\right)}$ & $\Delta H_{f}\left(\mathrm{~g}^{-1}\right)$ & \multicolumn{2}{|l|}{$\% \psi_{c}$} & $T_{c}\left({ }^{\circ} \mathrm{C}\right)$ \\
\hline & Before After & Before After & Before & e After & Before After \\
\hline HDPE & 133.2132 .1 & 183.2176 .3 & 63.2 & 60.9 & $112.3 \quad 110$ \\
\hline HDPE & $\begin{array}{ll}129.8 & 129.1\end{array}$ & $\begin{array}{ll}149.6 & 137.1\end{array}$ & 51.6 & 47.3 & $\begin{array}{ll}111.0 & 108.7\end{array}$ \\
\hline HDPE/E0109 & $\begin{array}{ll}131.6 & 129.8\end{array}$ & $154.7 \quad 135.9$ & 53.3 & 46.9 & $\begin{array}{lll}111.4 & 108.9\end{array}$ \\
\hline HDPE/EB & $131.0 \quad 129.6$ & 155.2 & 53.5 & 49.7 & $111.7 \quad 109.6$ \\
\hline HDPE/EVA & 132.3130 .0 & $\begin{array}{l}159.4 \quad 145.1 \\
\end{array}$ & 55.0 & 50.0 & $\begin{array}{lll}111.9 & 109.8\end{array}$ \\
\hline
\end{tabular}

(d)

\begin{tabular}{llll}
\hline Materials & Grafting index & $\begin{array}{l}\text { Rate of crosslinking } \\
\left(\% . \mathrm{hr}^{-1}\right)\end{array}$ & $\begin{array}{l}\text { Gel at 600 h } \\
(\%)\end{array}$ \\
\hline HDPE & $2.31 \pm 0.01$ & 1.65 & $80.03 \pm 1.24$ \\
HDPE/E076 & $2.15 \pm 0.05$ & 2.23 & $81.27 \pm 1.06$ \\
HDPE/E0109 & $2.03 \pm 0.02$ & 3.04 & $82.00 \pm 0.67$ \\
HDPE/EB & $2.24 \pm 0.06$ & 1.77 & $81.22 \pm 0.85$ \\
HDPE/EVA & $1.23 \pm 0.04$ & 3.69 & $83.35 \pm 0.67$ \\
\hline
\end{tabular}

(e)
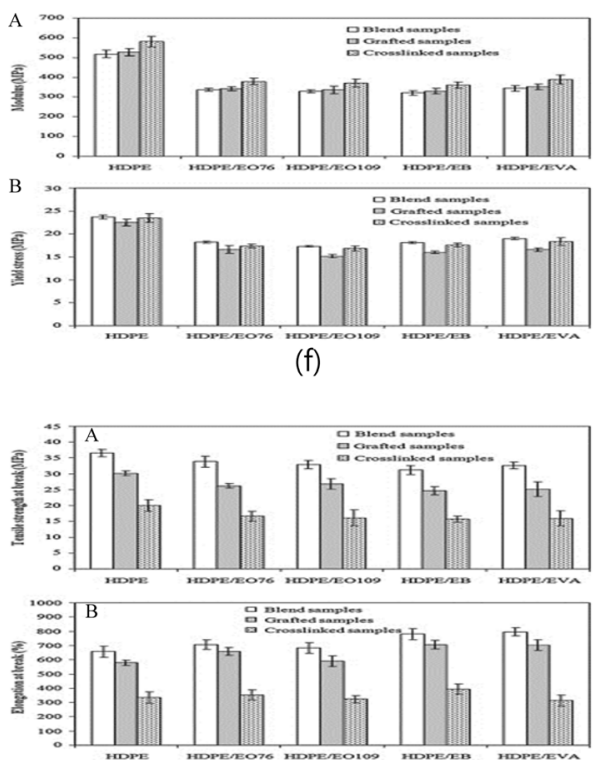

(g)

\begin{tabular}{|c|c|c|c|c|c|c|c|c|}
\hline \multirow[t]{2}{*}{ Nerials } & \multicolumn{2}{|c|}{$\mathrm{HDT}(\mathrm{C})$} & \multicolumn{2}{|c|}{ 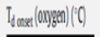 } & \multicolumn{2}{|c|}{ 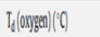 } & \multicolumn{2}{|c|}{$\left.\varepsilon(k) m^{-1}\right)$} \\
\hline & Before & Ather & Before & After & Before & Atter & Before & After \\
\hline HOPE & 66.0 & 93.0 & 3003 & 3415 & 4132 & 499 & 590.1 & 6259 \\
\hline HDFEEOT/6 & 0.5 & 8.5 & 319.1 & 302 & 4121 & 450 & 5334. & 6180. \\
\hline HDEFEONOO & 60.3 & 86.2 & 321.9 & 3394 & 4159 & 403 & 5862 & 619.7 \\
\hline HDFEEB & 61.5 & \&.] & 319.1 & 3390 & 442 & 40.1 & 57.1. & 6265 \\
\hline HDFEEA & 693 & 9.3 & 3122 & 3201 & 4173 & 452 & 5994 & 626 \\
\hline
\end{tabular}

(h)

Fig. 14. Effect of silane carriers on silane grafting of high density polyethylene (HDPE) and properties of cross-linked products. Reprinted with permission From [84]: (a) FTIR spectra of HDPE, grafted HDPE, and grafted HDPE blended with various silane carriers; (b) IR peak positions and their assignments; (c) crosslink density as a function of immersing time of various crosslinked HDPE; (d) melting temperature $\left(\mathrm{T}_{\mathrm{m}}\right)$, heat of fusion $\left(\Delta \mathrm{H}_{\mathrm{f}}\right)$, percentage of crystallinity $\left(\% x_{c}\right)$ and crystallisation temperature $\left(T_{c}\right)$ of various samples before and after performing a silane-crosslink reaction; (e) effect of silane carriers on the grafting index, rate of silane crosslinking, and gel content of various HDPE systems; (f) A modulus and B yield stress of unmodified, grafted and crosslinked systems; (g) A tensile strength at break and B elongation at break of unmodified, grafted and crosslinked systems; (h) effect of silane carrier on heat distortion temperature (HDT), onset of decomposition temperature ( $\left.T_{\text {donset }}\right)$, decomposition temperature $\left(T_{d}\right)$ and activation energy $\left(E_{d}\right)$ of thermal decomposition reaction of various samples before and after performing a silane-crosslink reaction.

siloxane crosslinks present in their structures were observed in the spectra of HDPE cross-linked with $3 \%$ and $4 \%$ silane. Those crosslinks did not significantly change the crystallinity of the PEXs, as confirmed by X-ray diffraction analysis. However, they ensured an improvement in the cross-linked HDPE thermal stability and creep resistance when compared to non-cross-linked HDPE (Fig. 13).

Sirisinha et al.'s [84] investigation of the silane grafting of HDPE indicated that the studied silane carriers (EVA, EB, and EO) could not improve the efficiency of grafting. The presence of bulky groups and steric side chains in the carrier molecules caused melt grafting difficulty. However, the silane carriers showed a positive influence on the water-crosslink reaction. The rate of cross-linking and density of the crosslink network increased with carrier addition. This was due to an increase in the amorphous region brought about by 


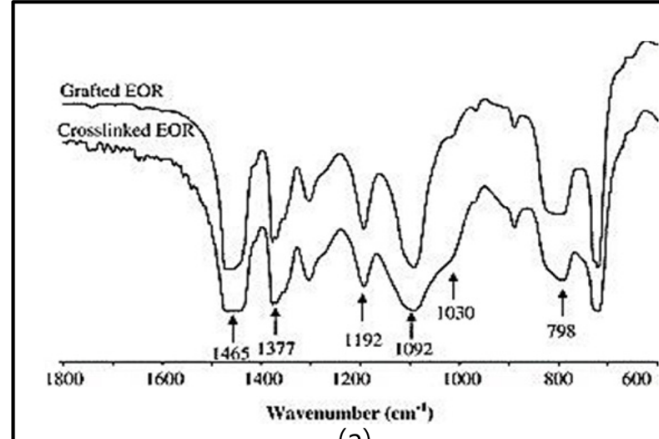

(a)
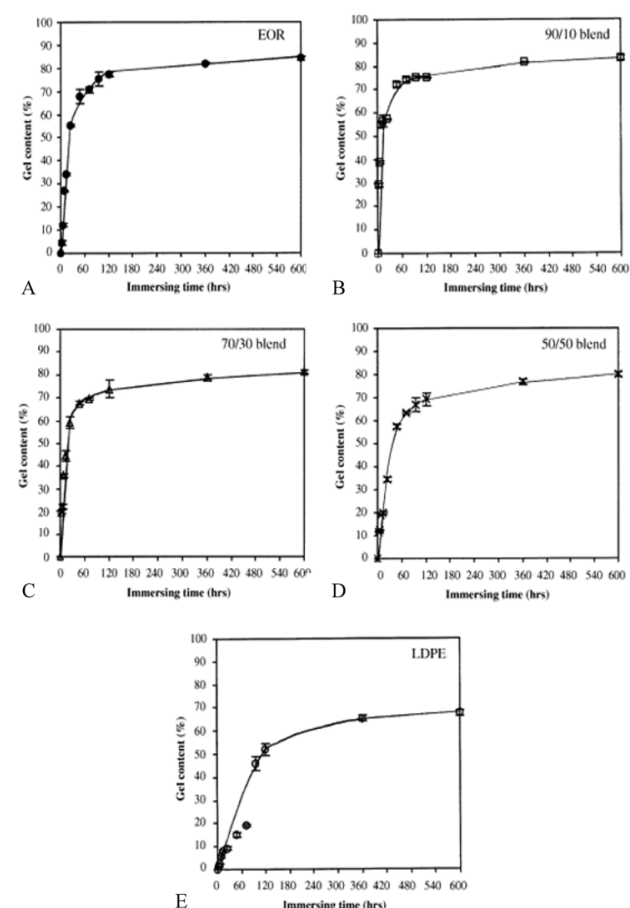

(b)

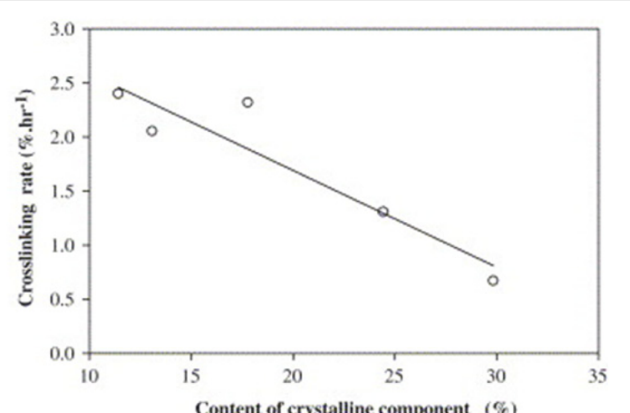

(c)
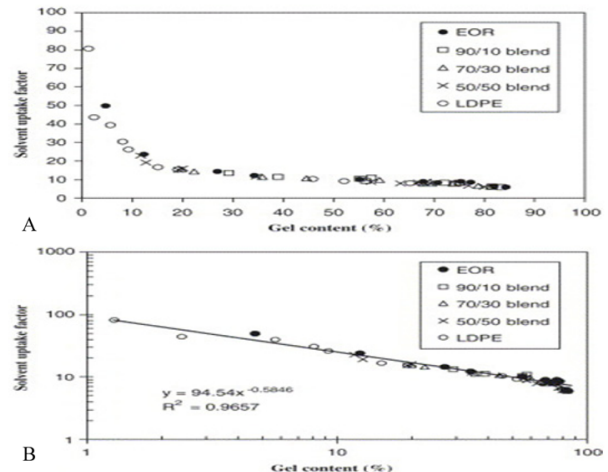

(d)

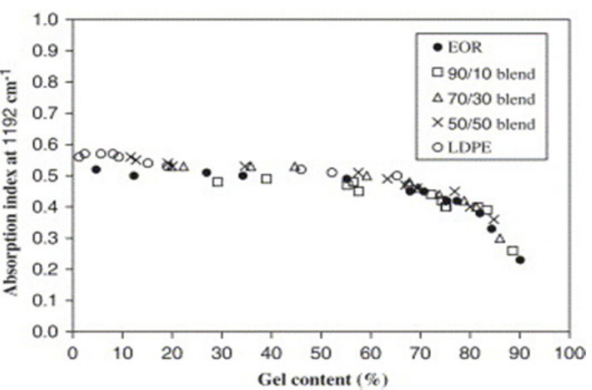

(e)

Fig. 15. Non-isothermal crystallization kinetics of peroxide-cross-linked polyethylene: effect of solid state mechanochemical milling. Reprinted with permission from [85]; (a) FTIR spectra of silane-grafted and crosslinked EOR samples; (b) effect of immersing time on gel content of various crosslinked samples A EOR, B 90/10 blend, C 70/30 blend, D 50/50 blend, and E LDPE; (c) crosslinking rate as a function of content of crystalline component in the crosslinked samples; (d) A relationship between solvent uptake factor and gel content. B logarithmic plot of solvent uptake factor and gel content; (e) relationship between IR absorption index and gel content.

the incorporation of the silane carrier, which facilitated the penetration of water during the curing step. Thermal analysis revealed a marked enhancement in the thermal properties of the HDPE after cross-linking. An increase in the temperature and activation energy of thermal decomposition as well as heat deflection temperature was observed. Moreover, an improvement in tensile yield stress and modulus also resulted from the silane cross-linking, along with a reduction in elongation at break (Fig. 14).

Sirisinha and Chimdist [85] also investigated silanewater cross-linked ethylene-octene copolymer (EOR) and EOR/LDPE blends for their degree of cross-linking. The characterization techniques used were the standard gel content determination method, the solvent uptake factor method, and FTIR analysis. The results showed that the cross-linking time and the content of the crystalline portion in the materials have an important effect on the degree and rate of cross-linking reaction. Comparing the three techniques investigated, it can be summarized that the measurement of gel content is a direct way to yield results on the degree of cross-linking. However, care must be taken when analyzing samples with low gel content by these techniques. Quantitative characterization of the FTIR data, especially a decrease in the absorption intensity of the methoxysilane groups, may not provide a direct cross-linking value, but the technique is non-destructive and presents meaningful information on the progress of the silane-water cross-linking reaction. The test is also less time consuming and needs no solvent, so is more environmentally friendly compared to the gel content determination and solvent up- 


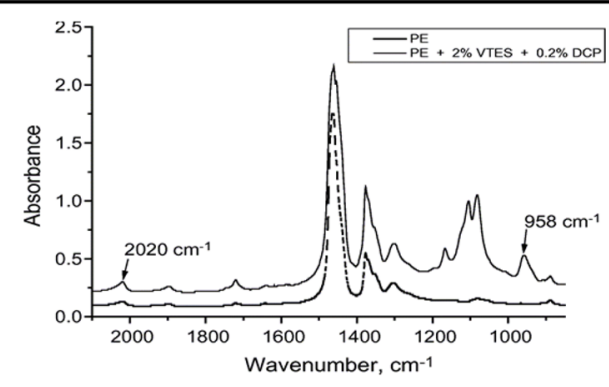

(a)

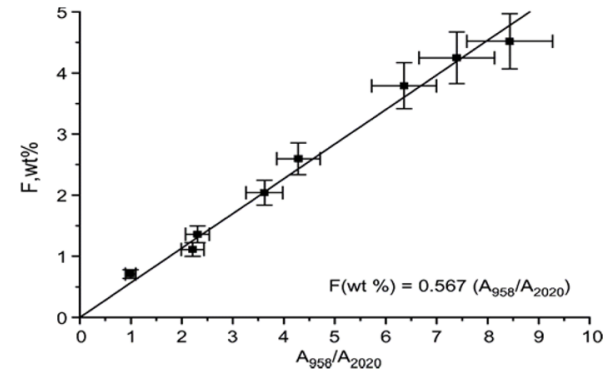

(b)

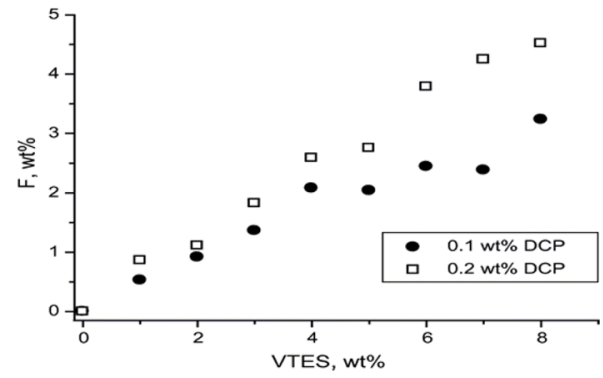

(c)

\begin{tabular}{lllll}
\hline Sample & DCP & $\begin{array}{l}\bar{M}_{\mathrm{n}} \times 10^{-3} \\
(\mathrm{~g} / \mathrm{mol})\end{array}$ & $\begin{array}{l}\bar{M}_{\mathrm{w}} \times 10^{-3} \\
(\mathrm{~g} / \mathrm{mol})\end{array}$ & $\begin{array}{l}\bar{M}_{\mathrm{w}} / \bar{M}_{\mathrm{n}} \\
(\mathrm{g} / \mathrm{mol})\end{array}$ \\
\hline $\mathrm{PE}$ & 0 & 10 & 58 & 5.8 \\
$\mathrm{PE}$ & 0 & 11 & 43 & 3.9 \\
$\mathrm{PE}$ & 0.1 & 16 & 120 & 7.5 \\
\hline
\end{tabular}

(d)

\begin{tabular}{lllc}
\hline Sample & $\begin{array}{l}\text { VTES } \\
\text { (wt.\%) }\end{array}$ & $\begin{array}{l}\text { DCP } \\
\text { (wt.\%) }\end{array}$ & $\begin{array}{l}\text { Gel fraction } \\
\text { (wt.\%) }\end{array}$ \\
\hline 1 & 0 & 0.1 & 0 \\
2 & 1 & 0.1 & 3 \\
3 & 3 & 0.1 & 26 \\
4 & 5 & 0.1 & 23 \\
5 & 7 & 0.1 & 44 \\
6 & 0 & 0.2 & 0 \\
7 & 1 & 0.2 & 18 \\
8 & 3 & 0.2 & 34 \\
9 & 5 & 0.2 & 40 \\
10 & 7 & 0.2 & 38 \\
11 & 4 & 0 & 22 \\
\hline a & \multicolumn{4}{l}{}
\end{tabular}

(e)

\begin{tabular}{lllll}
\hline $\begin{array}{l}\text { VTES } \\
\text { (wt. } \%)\end{array}$ & $\begin{array}{l}\text { DCP } \\
(\text { wt. } \%)\end{array}$ & $\begin{array}{l}\text { Crystallinity } \\
(\%)\end{array}$ & $T_{\mathrm{m}}\left({ }^{\circ} \mathrm{C}\right)$ & $T_{\mathrm{c}}\left({ }^{\circ} \mathrm{C}\right)$ \\
\hline 0 & 0 & 35.0 & 110.3 & 93.9 \\
1 & 0.1 & 33.5 & 108.9 & 92.7 \\
2 & 0.1 & 29.9 & 110.2 & 90.8 \\
3 & 0.1 & 28.2 & 109.6 & 90.8 \\
4 & 0.1 & 28.8 & 107.6 & 90.2 \\
5 & 0.1 & 26.5 & 109.5 & 89.8 \\
\hline
\end{tabular}

(f)

\begin{tabular}{llllllrr}
\hline Sample & VTES (wt.\%) & DCP (wt.\%) & $\begin{array}{l}\text { Final torque } \\
(\mathrm{N} \mathrm{m})\end{array}$ & F (wt.\%) & $\begin{array}{l}\text { Yield stress } \\
(\mathrm{MPa})\end{array}$ & $\begin{array}{l}\text { Elongation at } \\
\text { break (\%) }\end{array}$ & $\begin{array}{l}\text { Elastic modu- } \\
\text { lus (Mpa) }\end{array}$ \\
\hline Virgin PE & 0 & 0 & - & 0 & $7.0 \pm 0.2$ & $290 \pm 50$ & $168 \pm 19$ \\
Processed PE & 0 & 0 & 3.2 & 0 & $8.2 \pm 0.1$ & $217 \pm 7$ \\
PE-VTES1 & 0 & 0.1 & 4.0 & 0 & $9.2 \pm 0.7$ & $372 \pm 110$ & $221 \pm 5$ \\
PE-VTES2 & 0.5 & 0.1 & 4.3 & 0.2 & $5.4 \pm 0.6$ & $259 \pm 116$ & $127 \pm 17$ \\
PE-VTES3 & 3.0 & 0.1 & 4.4 & 1.4 & $6.2 \pm 0.3$ & $238 \pm 100$ & $123 \pm 15$ \\
PE-VTES4 & 7.0 & 0.1 & 4.7 & 2.4 & $5.1 \pm 0.2$ & $99 \pm 29$ & $127 \pm 9$ \\
\hline
\end{tabular}

(g)

Fig. 16. Free radical modification of low density polyethylene (LDPE) with vinyltriethoxysilane. Reprinted with permission from [70]; (a) infrared spectra of LDPE and PE-VTES; (b) correlation between degree of functionalization (F) determined by RBS and ratio A958 / A2020 obtained from FTIR ( $r=0.995$ ); (c) degree of functionalization as a function of VTES concentration for two DCP concentrations; (d) molecular weights of PE; (e) gel fraction of PE-VTES; ( $f$ ) crystallinity, melting temperature $\left(T_{m}\right)$ and crystallization temperature $\left(T_{c}\right)$ of PE and PE-VTES; (g) mechanical properties of PE and PE-VTES.

take factor methods (Fig. 15).

Fabris et al. [70] found that VTES easily grafted to melted LDPE in the presence of peroxide, up to $86 \%$ of conversion. The degree of functionalization increased with VTES and peroxide concentration though no functionalization was observed in the absence of peroxide. The absolute degree of functionalization could be determined by simple infrared analysis after relating them to Rutherford backscattering spectrometry results, with a good correlation factor ( $\mathrm{r}$ $=0: 995)$. Torque measurements and molecular weight determinations indicated the occurrence of chain combination for reactions performed in the presence of peroxide. Final torque did not change at all with the changing concentration of VTES, but after a few months' storage a significant gel fraction was observed, probably due to post-reactor combination reactions (Fig. 16).

\subsection{Sulfuric system}

Ihata [86] demonstrated the cyclization formation of $\mathrm{PE}$ via the cross-linked reaction of sulfuric acid in 1988. The reaction mechanism of the sulfuric acid with PE is represented 


$$
\begin{aligned}
& \mathrm{H}_{2} \mathrm{SO}_{4} \rightleftharpoons \mathrm{H}_{2} \mathrm{O}+\mathrm{SO}_{3}
\end{aligned}
$$

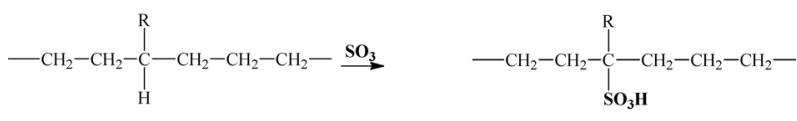

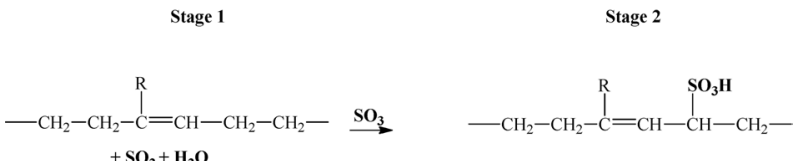

$$
\begin{aligned}
& \begin{array}{ll}
\text { Stage } 3 & \text { Stage } 4
\end{array} \\
& \begin{array}{c}
\underset{+\mathrm{H}_{2} \mathrm{O}}{\stackrel{\mathrm{SO}_{2}}{\longrightarrow}}-\mathrm{CH}_{2}-\mathrm{CH}_{2}-\stackrel{\mathrm{C}}{\mathrm{C}}=\underset{\mathrm{H}}{\mathrm{CH}}-\underset{\mathrm{C}}{\mathrm{C}}=\mathrm{CH}_{2} \\
\text { Stage } 5
\end{array}
\end{aligned}
$$

Fig. 17. Reaction mechanism of sulfuric acid with low density polyethylene, introducing sulfuric groups and carbon-to-carbon double bonds [86].

below as Fig. 17. In the reaction mechanism, the surface of te $\mathrm{PE}$ was sulfonated by reaction with gaseous $\mathrm{SO}_{3}$. It was confirmed that $\mathrm{PE}$ and $\mathrm{SO}_{3}$ gave unsaturated sulfonic acids and that, as the reaction proceeded, the elimination of sulfurous acids took place to form sulfonic acids having highly conjugated $\mathrm{C}=\mathrm{C}$ unsaturated bonds.

Younker et al. [87] sought to understand the pyrolysis pathways of sulfonated PE with the present Author, and studied the decomposition reactions of the model compound $\mathrm{H}_{4} \mathrm{~S}$.
Using density functional theory and transition state theory, the author determined the rate constants for the internal elimination and radical chain reaction mechanism for the pyrolysis of $\mathrm{H}_{4} \mathrm{~S}$.

Nonlinear Arrhenius plots were found for all bimolecular reactions. To report and interpret rate constants, we used the Kooij equation. For reactions with low activation barriers, nonlinearity was traced to conflicting trends between the exponential temperature dependence of the energetic term and the vibrational partition function of the transitional modes. For reactions with high activation energies, the exponential term was dominant, and the Arrhenius plot approached linearity. This work represents the first study of $\mathrm{E}_{\mathrm{i}} 5$ elimination in alkane sulfonic acid derivatives. Two different reaction barriers were found (50 and $60 \mathrm{kcal} / \mathrm{mol}$ ), depending on the placement of the HO-group in the sulfonic acid. $\mathrm{R}-\mathrm{CHSO}_{3} \mathrm{H}$ rotation from the reactant to the transition state yielded a cis-alkene. The decomposition of the product, $\mathrm{H}_{2} \mathrm{SO}_{3}$, was aided catalytically by $\mathrm{H}_{2} \mathrm{O}$, with a barrier of $16 \mathrm{kcal} / \mathrm{mol}$. Following the radical abstraction of the $\alpha-\mathrm{H}$ from $\mathrm{H} 4 \mathrm{~S}$, first order decomposition of the radical intermediate yielded the trans-alkene and $\mathrm{HOSO}_{2}$. At temperatures $<440 \mathrm{~K}$, the amount of $\mathrm{H} 4 \mathrm{~S}$ converted to the olefin was insignificant. At higher temperatures, $\mathrm{HOSO} \dot{\mathrm{O}}_{2}$ underwent decomposition to $\dot{\mathrm{OH}}+\mathrm{SO}_{2}$, which allowed for rapid $\alpha-\mathrm{H}$ abstraction by $\dot{\mathrm{O}} \mathrm{H}$. Given the reported BDEs for the resulting olefin, we predicted that the increasing presence of unsaturated bonds during the course of pyrolysis will augment the amount of $\dot{\mathrm{O} H}$, and

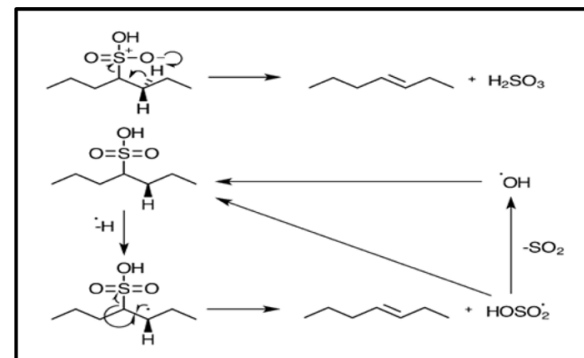

(a)

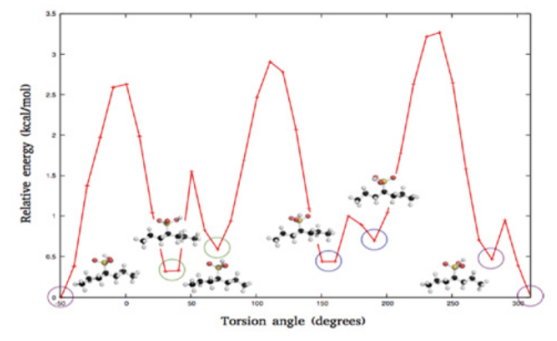

(c)

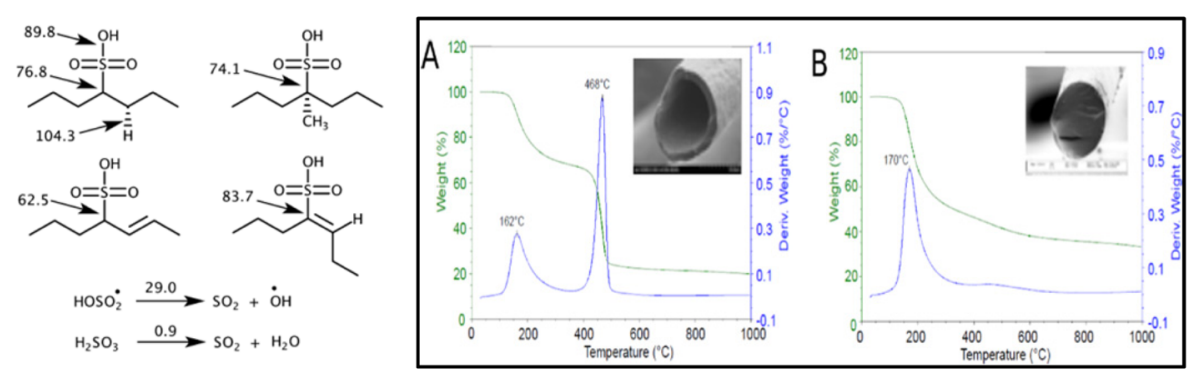

(b)

(d)

Fig. 18. Pyrolysis pathways of sulfonated polyethylene, an alternative carbon fiber precursor. Reprinted with permission from [87]: (a) scheme showing Ei5 elimination (top) and the radical chain reaction (bottom) for H4S; (b) M06-2X/6-311++G(3df,3pd)//M06-2X/6-31G** BDEs in kcal/mol at 298 K; (c) binned minima from $\mathrm{R}-\mathrm{SO} 3 \mathrm{H}$ rotational coordinate. Reactant $\mathrm{A}$ is in purple, $\mathrm{B}$ is in green, and $\mathrm{C}$ is in blue; (d) A TGA thermogram of partially functionalized PE fiber (inset: scanning electron micrograph of pyrolyzed fiber from a partially sulfonated polyethylene). B TGA thermogram of fully functionalized PE fiber (inset: scanning electron micrograph of pyrolyzed fiber from a fully sulfonated polyethylene). 


\begin{tabular}{|c|c|c|c|c|c|}
\hline $\mathrm{C}_{7} \mathrm{H}_{14}+\mathrm{H}_{2} \mathrm{SO}_{3} \rightarrow \mathrm{C}_{7} \mathrm{H}_{15} \mathrm{SO}_{3} \mathrm{H}$ & $300-1000$ & -6.82 & 2.71 & 26.50 & $2.197 \times 10^{-9}$ \\
\hline \multicolumn{6}{|c|}{$\mathrm{H}_{2} \mathrm{SO}_{3}$ Decomposition (Shared in Both Mechanisms) } \\
\hline $\mathrm{H}_{2} \mathrm{SO}_{3} \rightarrow \mathrm{SO}_{2}+\mathrm{H}_{2} \mathrm{O}$ & $300-1000$ & 29.36 & 0.00 & 27.79 & $1.738 \times 10^{-1}$ \\
\hline $\mathrm{SO}_{2}+\mathrm{H}_{2} \mathrm{O} \rightarrow \mathrm{H}_{2} \mathrm{SO}_{3}$ & $300-1000$ & -3.65 & 2.68 & 25.60 & $1.220 \times 10^{-7}$ \\
\hline \multirow[t]{2}{*}{$\mathrm{H}_{2} \mathrm{SO}_{3}+\mathrm{H}_{2} \mathrm{O} \rightarrow \mathrm{SO}_{2}+2 \mathrm{H}_{2} \mathrm{O}$} & $300-400$ & 10.26 & 0.51 & 2.04 & \\
\hline & $400-1000$ & -0.47 & 2.01 & 0.66 & $6.465 \times 10^{4}$ \\
\hline \multicolumn{6}{|c|}{ Radical Chain Reaction } \\
\hline \multirow{2}{*}{$\mathrm{C}_{7} \mathrm{H}_{15} \mathrm{SO}_{3} \mathrm{H}+\mathrm{OH} \rightarrow \mathrm{C}_{7} \mathrm{H}_{14} \mathrm{SO}_{3} \mathrm{H}+\mathrm{H}_{2} \mathrm{O}$} & $300-800$ & -12.77 & 4.70 & -6.96 & $1.988 \times 10^{10}$ \\
\hline & $800-1000$ & -4.77 & 3.65 & -5.41 & \\
\hline $\mathrm{C}_{7} \mathrm{H}_{14} \mathrm{SO}_{3} \mathrm{H}+\mathrm{H}_{2} \mathrm{O} \rightarrow \mathrm{C}_{7} \mathrm{H}_{15} \mathrm{SO}_{3} \mathrm{H}+\mathrm{OH}$ & $300-1000$ & -8.26 & 3.74 & 16.99 & $1.203 \times 10^{-2}$ \\
\hline $\mathrm{C}_{7} \mathrm{H}_{14} \mathrm{SO}_{3} \mathrm{H} \rightarrow \mathrm{C}_{7} \mathrm{H}_{14}+\mathrm{HOSO}_{2}$ & $300-1000$ & 34.27 & 0.00 & 13.05 & $3.426 \times 10^{8}$ \\
\hline \multirow{2}{*}{$\mathrm{C}_{7} \mathrm{H}_{14}+\mathrm{HOSO}_{2} \rightarrow \mathrm{C}_{7} \mathrm{H}_{14} \mathrm{SO}_{3} \mathrm{H}$} & $300-600$ & -3.08 & 2.68 & -3.17 & $2.074 \times 10^{7}$ \\
\hline & $600-1000$ & -2.45 & 2.59 & -3.07 & \\
\hline \multirow{2}{*}{$\mathrm{C}_{7} \mathrm{H}_{15} \mathrm{SO}_{3} \mathrm{H}+\mathrm{HOSO}_{2} \rightarrow \mathrm{C}_{7} \mathrm{H}_{14} \mathrm{SO}_{3} \mathrm{H}+\mathrm{H}_{2} \mathrm{SO}_{3}{ }^{d}$} & $300-550$ & -9.45 & 2.99 & -2.86 & $1.615 \times 10^{5}$ \\
\hline & $550-1000$ & -61.06 & 9.98 & -11.11 & \\
\hline \multirow{2}{*}{$\mathrm{C}_{7} \mathrm{H}_{14} \mathrm{SO}_{3} \mathrm{H}+\mathrm{H}_{2} \mathrm{SO}_{3} \rightarrow \mathrm{C}_{7} \mathrm{H}_{15} \mathrm{SO}_{3} \mathrm{H}+\mathrm{HOSO}_{2}$} & $300-700$ & -12.37 & 3.05 & -8.76 & $9.751 \times 10^{6}$ \\
\hline & $700-1000$ & -69.27 & 10.69 & -18.35 & \\
\hline $\mathrm{HOSO}_{2} \rightarrow \mathrm{SO}_{2}+\mathrm{OH}$ & $300-1000$ & 32.40 & 0.00 & 28.56 & $1.504 \times 10^{0}$ \\
\hline \multirow[t]{2}{*}{$\mathrm{SO}_{2}+\mathrm{OH} \rightarrow \mathrm{HOSO}_{2}$} & $300-400$ & 9.42 & 1.42 & -0.95 & $2.085 \times 10^{8}$ \\
\hline & $400-1000$ & 3.96 & 2.19 & -1.61 & \\
\hline HOSO $_{2}+\mathrm{H}_{2} \mathrm{O} \rightarrow \mathrm{SO}_{2}+\mathrm{H}_{2} \mathrm{O}+\mathrm{OH}$ & $300-1000$ & -3.76 & 2.72 & 31.09 & $3.014 \times 10^{-10}$ \\
\hline
\end{tabular}

${ }^{a}$ Rate data in black (italic) font increased (decreased) with temperature. Rates in bold had atypical behavior. ${ }^{b}$ Depending on formation order, the rate constant $k$ has units of $\mathrm{s}^{-1}$ or $\mathrm{M}^{-1} \mathrm{~s}^{-1}$, where $k_{i}^{\prime}=B T^{\alpha} \mathrm{e}^{-E_{0} / R T}$. ${ }^{c} E_{0}$ has units of $\mathrm{kcal} / \mathrm{mol}$. ${ }^{d}$ Alternatively $\mathrm{SO}_{2} \mathrm{OH}_{2}$, which decomposes to $\mathrm{SO}_{2}+$ $\mathrm{H}_{2} \mathrm{O}$.

(a)

A
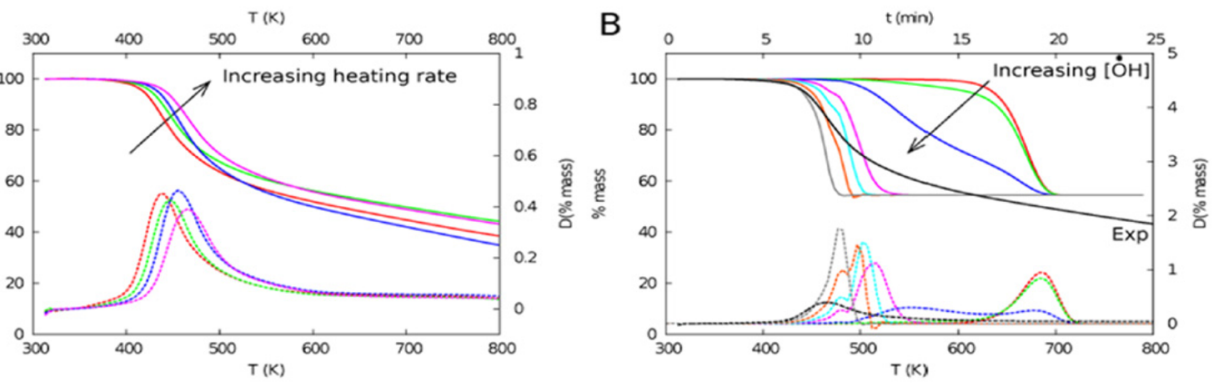

C

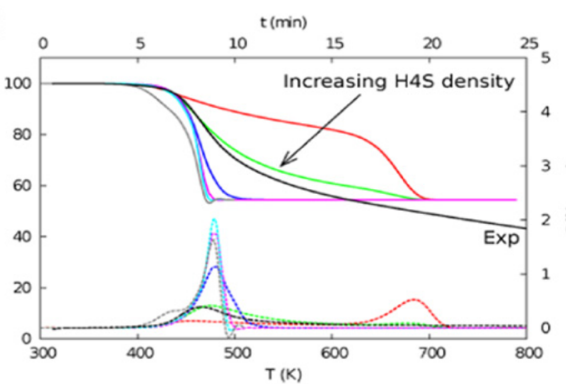

$\mathrm{D}$

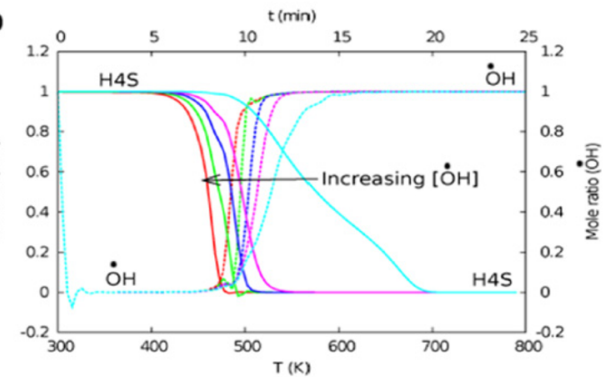

(b)

Fig. 18. Continued: (a) M06-2X/6-311++G(3df,3pd)//6-31G** Kooij Parameters from 300 to $1000 \mathrm{~K}$ for Various Reaction Steps ${ }^{\mathrm{a}}$; (b) A experimental TGAs based on sulfonated PE at heating rates of 2.5 (red), 5 (green), 10 (blue), and 20 (pink) ${ }^{\circ} \mathrm{C} / \mathrm{min}$. B H4S kMC simulations $\left(1.6 \mathrm{ng} \mathrm{mL}-120^{\circ} \mathrm{C} / \mathrm{min}\right)$ detailing TGA dependence on $\mathrm{O}^{\circ} \mathrm{H} / \mathrm{H} 4 \mathrm{~S}$ ratio: $3.3 \times 10^{-7}$ (red), $3.3 \times 10^{-6}$ (green), $3.3 \times 10^{-5}$ (blue), $3.3 \times 10^{-4}$ (pink), $6.7 \times 10^{-4}$ (aqua), $1.3 \times 10^{-3}$ (orange), $2.7 \times 10^{-3}$ (gray), and experimental (black, based on sulfonated PE). C H4S kMC simulations $\left(20^{\circ} \mathrm{C} / \mathrm{min}\right.$ ) detailing TGA dependence on $\mathrm{H} 4 \mathrm{~S}$ density (first number) and high $\mathrm{O}{ }^{\circ} \mathrm{H} /$ H4S ratio (second number): $1.6 \mathrm{pg} \mathrm{mL}^{-1}, 6.7 \times 10^{-3}$ (red); $16 \mathrm{pg} \mathrm{mL}^{-1}, 3.3 \times 10^{-3}$ (green); $160 \mathrm{pg} \mathrm{mL}^{-1}, 2.7 \times 10^{-3}$ (blue); $1.6 \mathrm{ng} \mathrm{mL}^{-1}, 2.7 \times 10^{-3}$ (pink); $16 \mathrm{ng} \mathrm{mL}^{-1}, 2.7$ $\times 10^{-3}$ (aqua); $160 \mathrm{ng} \mathrm{mL}-1 ; 2.7 \times 10^{-3}$ (gray); and experimental (black, based on sulfonated PE). D TGA $\left(1.6 \mathrm{ng} \mathrm{mL}^{-1} 20^{\circ} \mathrm{C} / \mathrm{min}\right.$ ) mole ratio of $\mathrm{H}_{4} \mathrm{~S}$ and $\mathrm{O}^{-1} \mathrm{H}$ as a function of temperature/time with $\mathrm{O}^{\circ} \mathrm{H} / \mathrm{H} 4 \mathrm{~S}$ ratio: $3.3 \times 10^{-5}$ (aqua), $3.3 \times 10^{-4}$ (pink), $6.7 \times 10^{-4}$ (blue), $1.3 \times 10^{-3}$ (green), and $2.7 \times 10^{-3}$ (red). See the Supporting Information for all TGAs.

will therefore increase the available amount of free radical to initiate the radical chain [87-95].

Younker et al. [87] have used $\mathrm{kMC}$, in conjunction with design for testing (DFT)/threshold testing (TST) determined rate constants, to simulate thermosgravimetric analysis (TGAs), which were used experimentally to follow pyrolysis. We found two regions in the TGA that were dominated by different mechanisms. At temperatures $>600 \mathrm{~K}$, a concerted unimolecular reaction was present that produced a cis-alkene. At temperatures from 440 to $550 \mathrm{~K}$, a radical reaction produced a trans-alkene. In this region, the maximum rates of change in \% mass occurred from 440 to $480 \mathrm{~K}$, depending on heating rate. At these temperatures, $\mathrm{HOSO}_{2}$ decomposed and $\dot{\mathrm{OH}}$ became the radical responsible for propagation of the 


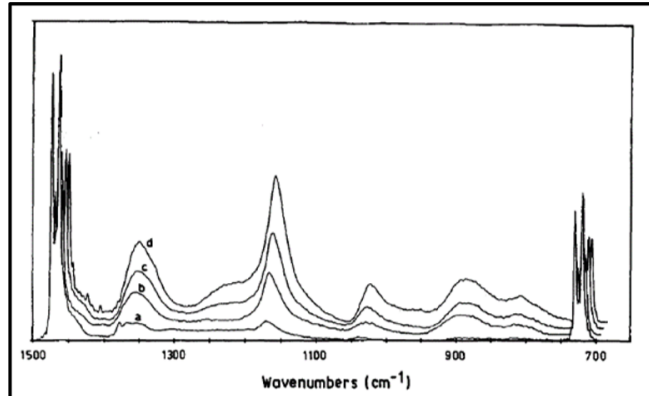

(a)

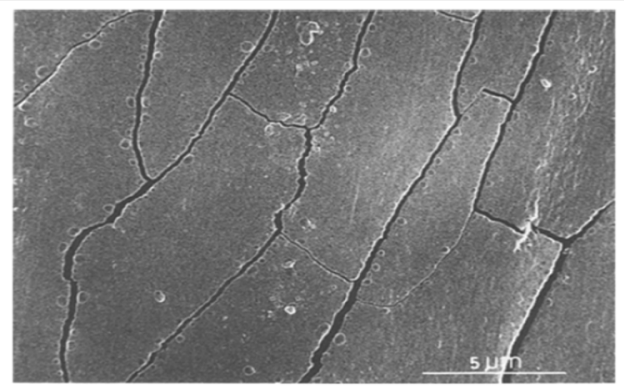

(b)

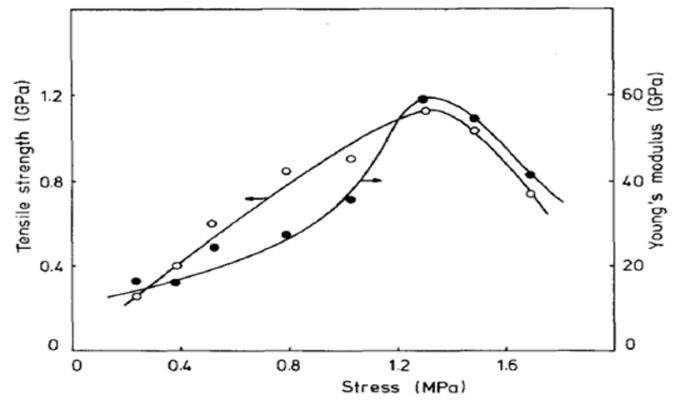

(c)

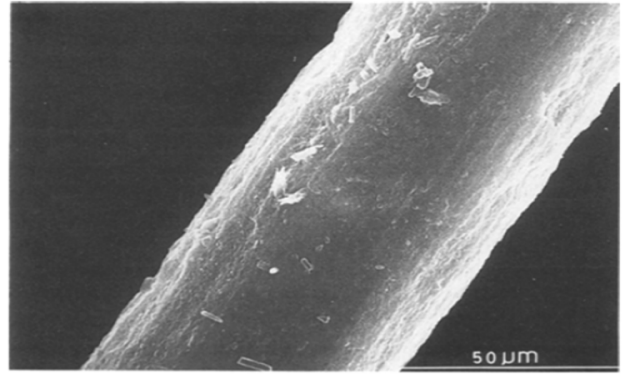

(d)

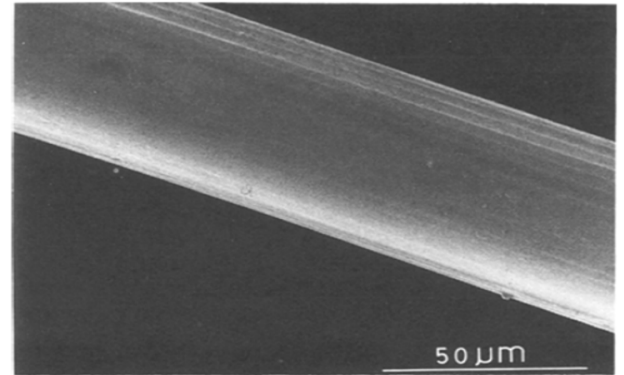

(e)

Fig. 19. Morphology and mechanical properties of amorphous carbon fibers from linear low density polyethylene. Reprinted with permission from [110]: (a) IR spectra of LLDPE films treated with chlorosulphonic acid for different periods of time. At = $30 \mathrm{~min}, \mathrm{bt}=1 \mathrm{~h}, \mathrm{ct}=2 \mathrm{~h}, \mathrm{dt}=4 \mathrm{~h}$; (b) SEM micrograph of the surface of a chlorosulphonated LLDPE fibre showing longitudinal and perpendicular cracks (fibre B); (c) tensile strength and Young's modulus of carbon fibres obtained from precursor B (chlorosulphonation time 12h) as a function of applied stress (heat-treatment temperature $900^{\circ} \mathrm{C}$; heat-treatment time $5 \mathrm{~min}$ ); (d) SEM micrograph of the surface texture of a carbon fibre made at $900 \sim \mathrm{C}$ from precfirsor A (heat-treatment time $5 \mathrm{~min}$, stress $0.10 \mathrm{MPa}$ ); (e) SEM micrograph of the surface texture of a carbon fibre made at $900 \sim \mathrm{C}$ from precursor B (heat-treatment time 5 rain, stress $1.3 \mathrm{MPa}$ ).

chain reactions. The maximum rates of change in the radical region of the TGA agree with what was observed experimentally (440-460 K). Low-scale pyrolysis of sulfonated PE utilizes temperatures $<620 \mathrm{~K}$, making the radical mechanism the dominant pathway in the production of carbonaceous unsaturated hydrocarbon that, subsequently, undergoes carbonization at very high temperature. Such carbonization studies will be conducted in future investigations, as shown in Fig. $18 \mathrm{a}$ and $\mathrm{b}$ [96-109].

Postema et al. [110] researched melt-spun LLDPE fibers which were made infusible by treatment with chlorosulphonic acid. The cross-linked fibers were pyrolyzed within $5 \mathrm{~min}$ at temperatures between $600^{\circ} \mathrm{C}$ and $1100^{\circ} \mathrm{C}$ under tension, in a nitrogen atmosphere. CFs prepared at $900^{\circ} \mathrm{C}$, had a tensile strength of $1.15 \mathrm{GPa}$ and a Young's modulus of $60 \mathrm{GPa}$. The elongation at break was extremely high, up to $3 \%$. The carbon yield of the process was $72 \%$ to $75 \%$ (Fig. 19).

Penning et al. [111] researched the pronounced effect of the diameter of LLDPE-based CFs on their strength and modulus, and these properties could be improved considerably by using thin precursor fibers. Thin LLDPE filaments were obtained by application of elevated spinline temperatures in the melt-spinning process, which led to an improvement of the maximum attainable draw-down ratio. Careful carbonization of these filaments gave $17 \mu \mathrm{m}$ thick CFs with a tensile strength of $1.90 \mathrm{GPa}$ and a modulus of $148 \mathrm{GPa}$. By additional hot-drawing of the melt-spun filaments, even thinner precursor fibers were obtained, that could be converted to $13 \mu \mathrm{m} \mathrm{CFs}$, with a strength of 2.16 $\mathrm{GPa}$ and a modulus of $130 \mathrm{GPa}$. It was necessary to anneal 


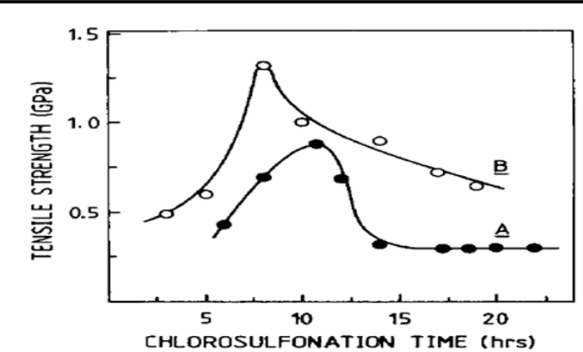

(a)

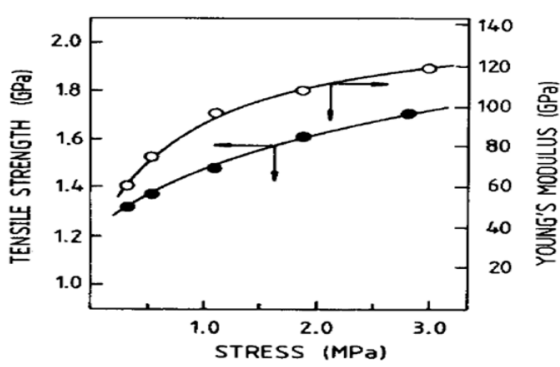

(b)

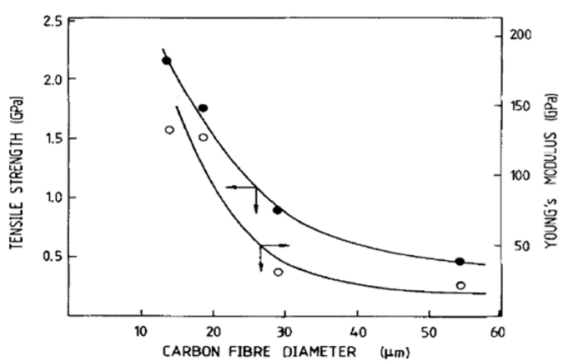

(c)

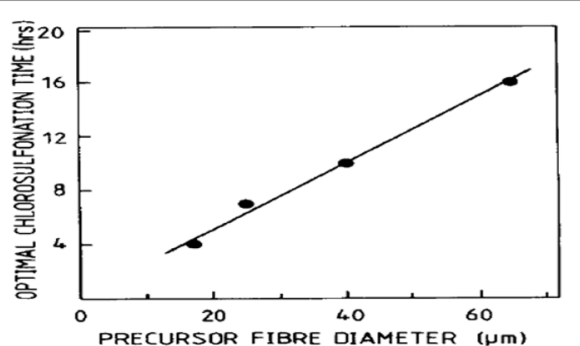

(d)

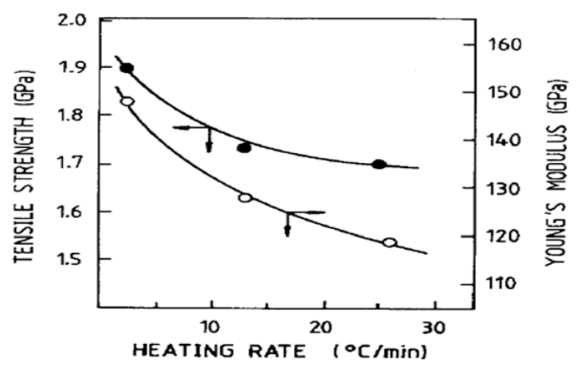

(e)

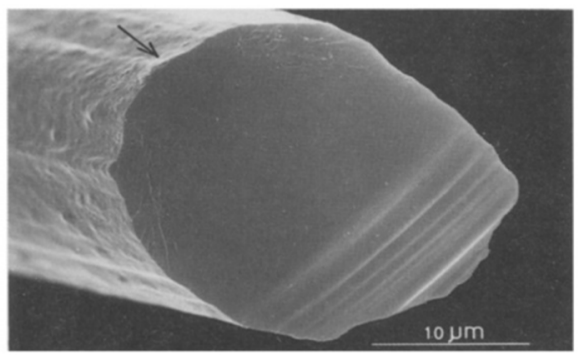

(f)

Fig. 20. Mechanical properties of amorphous carbon fibers from linear low density polyethylene, due to diameter. Reprinted with permission from [111]: (a) effect of chlorosulfonation time on the mechanical properties of carbon fibres, prepared from fibre $A(\bullet)$ and fibre B (o); (b) effect of fibre stress during pyrolysis of fibre $B$ on the mechanical properties of the resulting carbon fibres. Heating rate : $26^{\circ} \mathrm{C} / \mathrm{min}$; (c) effect of carbon fibre diameter on the ultimate mechanical properties; (d) optimal chlorosulfonation time as a function of precursor fibre diameter); (e) effect of heating rate during pyrolysis of fibre $\mathrm{B}$ on the mechanical properties of the resulting carbon fibres. Fibre stress : $2.8 \mathrm{Mpa}$; $(\mathrm{f})$ scanning electron micrograph of the fracture surface of a $1.90 \mathrm{GPa}$ carbon fibre.

the hot-drawn fibers in order to remove the residual stresses introduced by hot-drawing. Most likely, the diameter effect arises from the presence of a strong and stiff outer sheath, whose contribution to the mechanical properties is more dominant in thinner CFs (Fig. 20).

Zhang and Sun [54] have shown that CFs can be manufactured from partially drawn PE and highly oriented PE precursors. Both precursor fibers could be stabilized by sulfonation and the stabilization time decreased to $45 \mathrm{~min}$ from $130^{\circ} \mathrm{C}$ to $170^{\circ} \mathrm{C}$ compared with highly oriented PE fibers. The stabilized fibers were carbonized at $1100^{\circ} \mathrm{C}$ for $2 \mathrm{~min}$. Tensile properties of the $\mathrm{CF}$, at this stage, were reasonably good with a tensile strength of $2 \mathrm{GPa}$ and Young's modulus of $200 \mathrm{GPa}$. The elongation at break was less than $1 \%$. These precursors are quite promising and, by controlling tension during stabilization, CFs with superior mechanical properties may be produced (Fig. 21).

Kim et al. [48] have shown that LDPE could be used as a precursor and cross-linked by sulfuric acid to obtain a high degree of carbonization. The cross-linking behaviors of the samples were clearly observed with increasing reaction temperatures in sulfuric acid from DSC results. From the TGA results, the residues of the samples increased gradually up to $150^{\circ} \mathrm{C}$ of reaction temperature, then were dramatically enhanced at $170^{\circ} \mathrm{C}$. This result indicates that the cross-linking reaction of the LDPE in sulfuric acid can occur at low temperature, but high temperature (over $170^{\circ} \mathrm{C}$ ) can radically accelerate the cross-linking reaction. The final residue of 'PE-S-170' was over $50 \%$. In addition, the fibrous states of the samples were clearly observed to be carbonized fibers from the SEM results. From the results, LDPE can be a potentially advantageous material as a CF precursor (Fig. 22).

\section{Conclusion}

This review study, besides focusing on details of PE-based 


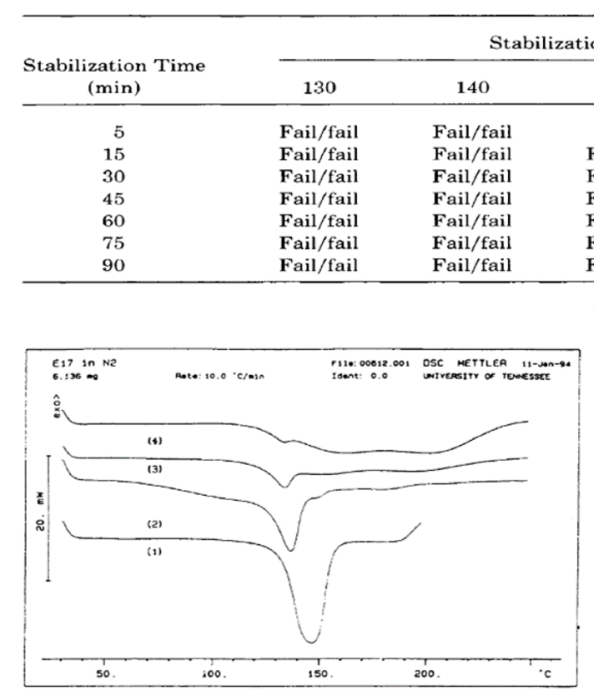

(b)

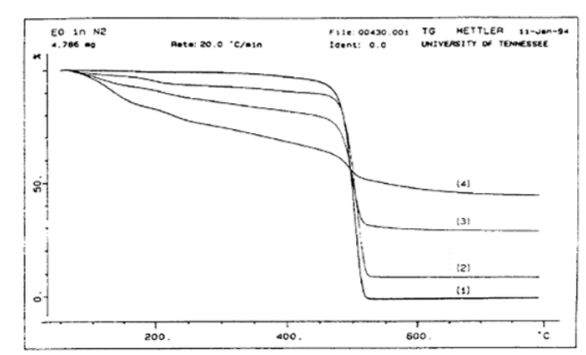

(d)
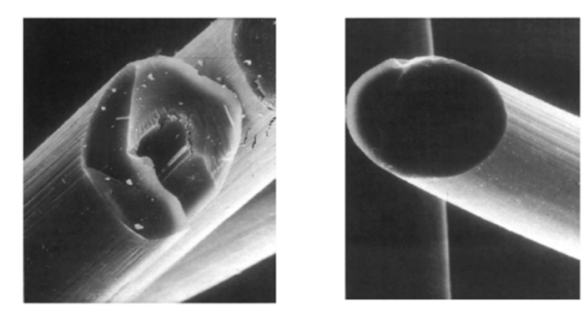

$(f)$

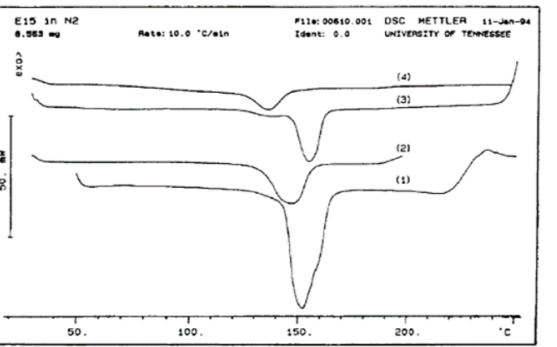

(c)

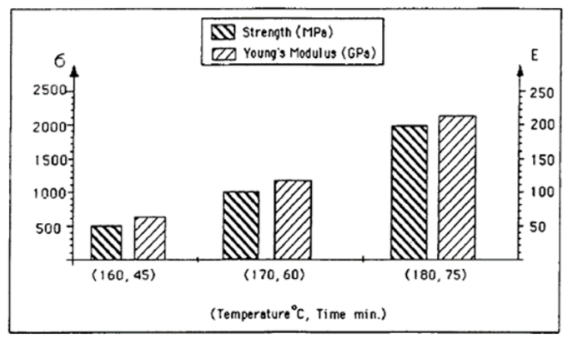

(e)
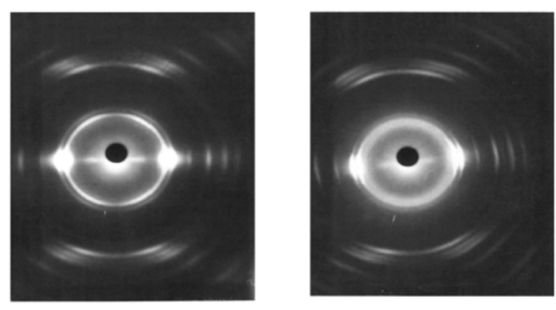

(g)

Fig. 21. Structure and properties during the conversion of polyethylene precursors to carbon fibers. Reprinted with permission from [54]: (a) burning Testing for Stabilized Fibers; (b) DSC scans of fiber samples stabilized at different temperatures and time. (1) Precursor, (2) $150^{\circ} \mathrm{C}$ and $30 \mathrm{~min}$, (3) $160^{\circ} \mathrm{C}$ and $45 \mathrm{~min},(4) 170^{\circ} \mathrm{C}$ and $60 \mathrm{~min}$; (c) DSC scans for differences between highly oriented polyethylene and partially drawn polyethylene. (1) Highly oriented polyethylene, (2) partially drawn polyethylene, (3) HOPE stabilized at $150^{\circ} \mathrm{C}$ for $60 \mathrm{~min}$, (4) PDPE stabilized at $150^{\circ} \mathrm{C}$ for $30 \mathrm{~min}$; (d) TGA scans (in nitrogen) of' fiber samples stabilized at different temperatures and time. (1) Precursor, (2) $150^{\circ} \mathrm{C}$ and $30 \mathrm{~min}$, (3) $160^{\circ} \mathrm{C}$ and $45 \mathrm{~min}$, (4) $170^{\circ} \mathrm{C}$ and $60 \mathrm{~min}$; (e) tensile properties of resultant carbon fibers; (f) SEM photographs of resultant carbon fibers from a) insufficient stabilization and b) sufficient stabilization; (g) X-ray diffraction photographs of fiber samples. a) precursor, b) partially stabilized.

low cost $\mathrm{CF}$, was also intended to introduce and investigate the different methods of preparing XLPE. The descriptions provided here of the available methods of XLPE, by sulfonic acid, peroxide, silane and radiation methods, demonstrate that all methods provide a common and efficient approach to XLPE.

The cross-linking behaviors of PE were clearly observed with increasing reaction time for all methods, based on thermal properties and gel content results. But, the silane, radiation, and DCP cross-linked methods were inappropriate as PE stabilization methods for $\mathrm{CF}$, because of their low cross- linking density. The sulfonic acid cross-linked method resulted in XLPE with a high cross-linking density, but it lacked cross-linking uniformity and produced surface destruction. The sulfonic acid cross-linking method can achieve a high carbonization yield (over 50\%) for the manufacture of CFs. When producing a $\mathrm{CF}$ using the sulfuric acid cross-linking method, hollowness and fractures were generated in the $\mathrm{CF}$ due to non-uniform cross-linking. The PE based CF production process required multiple cross-linked (a 1st low crosslinking density and a 2 nd high cross-linking density) and precision in the cross-linking process. 


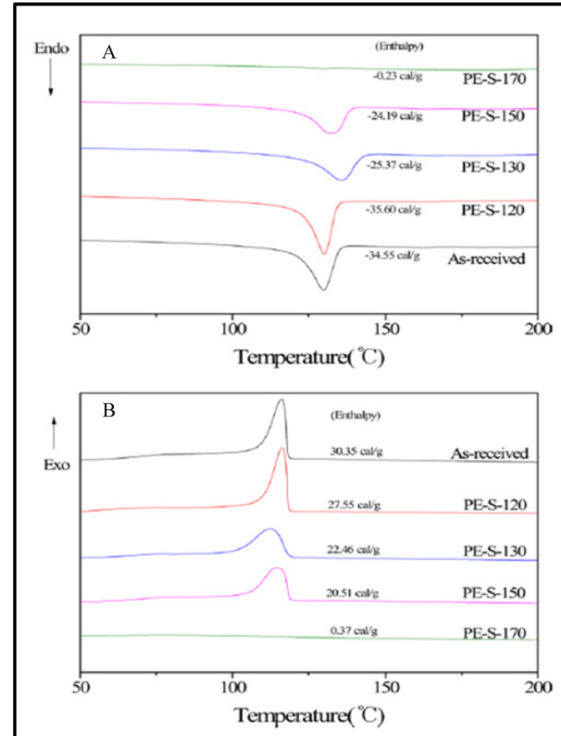

(a)

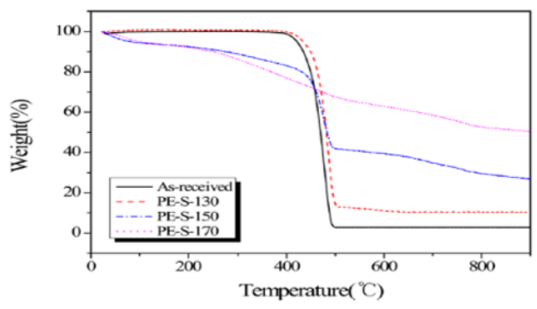

(b)
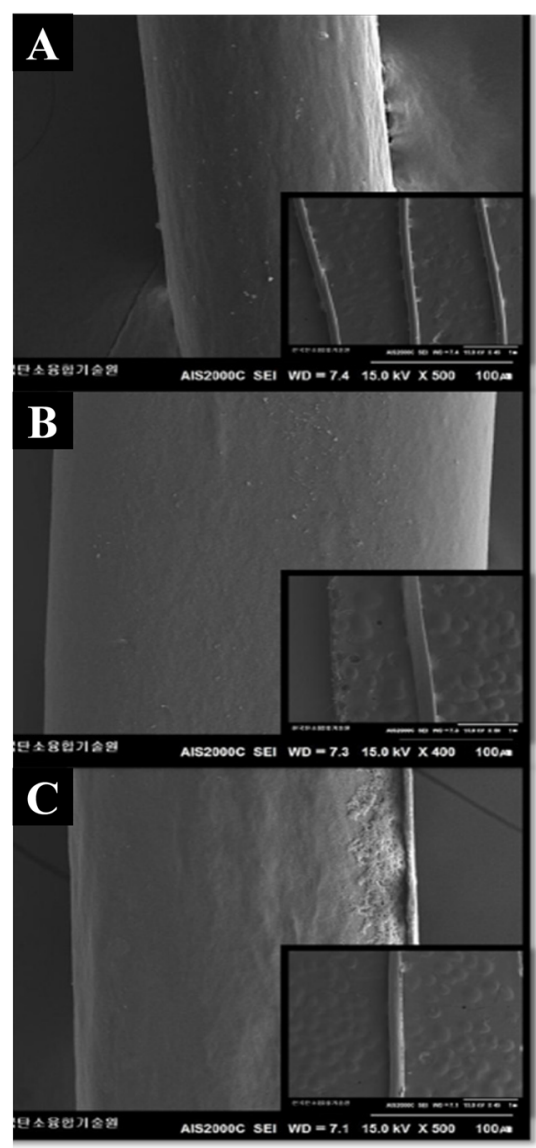

(c)

\begin{tabular}{ccccccc}
\hline TGA & PDT $\left({ }^{\circ} \mathrm{C}\right)$ & $\mathrm{T}_{\operatorname{mxx}}\left({ }^{\circ} \mathrm{C}\right)$ & $\mathrm{A}^{\prime} \mathrm{K}^{*}$ & IPDT $\left({ }^{\circ} \mathrm{C}\right)$ & Carbon yield $^{\mathrm{a}}(\%)$ & Fibrous form $^{\mathrm{b}}$ \\
\hline As-received & 447.32 & 472.80 & 0.541 & 501.18 & 2.78 & $\mathrm{x}$ \\
PE-S-130 & 462.29 & 483.26 & 0.70 & 637.67 & 10.44 & $\mathrm{x}$ \\
PE-S-150 & 454.33 & 477.58 & 1.10 & 985.66 & 26.82 & $\Delta$ \\
PE-S-170 & 238.43 & 492.32 & 2.30 & 2029.73 & 50.27 & 0 \\
\hline
\end{tabular}

: In the carbonization furnace

$\mathrm{b}: \mathrm{x}$-failed to form, $\triangle$-surface-fractured fiber, $\mathrm{O}$ - stable fiber

(d)

Fig. 22. Mechanical properties of amorphous carbon fibers from linear low density polyethylene, due to diameter [48]: (a) DSC curves of the cross-linked LDPE fibers treated by sulfuric acid with different temperatures. A heating B and cooling scan; (b) TGA curves of the cross-linked LDPE fibers treated by sulfuric acid with different temperatures; (c) SEM image of the cross-linked LDPE fibers treated by sulfuric acid: A As-received, B cross-linked LDPE fibers, C carbonized LDPE fiber; (d) TGA curve parameters of the cross-linked LDPE treated by sulfuric acid with different temperatures.

\section{Acknowledgments}

This research was financially supported by the Carbon Valley R\&D Project (Project no. A000600040) funded by the Ministry of Trade, Industry \& Energy (MOTIE), Republic of Korea.

\section{References}

[1] Fitzer E. Pan-based carbon fibers: present state and trend of the technology from the viewpoint of possibilities and limits to in- fluence and to control the fiber properties by the process parameters. Carbon, 27, 621 (1989). http://dx.doi.org/10.1016/00086223(89)90197-8

[2] Park SJ, Kim BJ. Carbon fibers and their composites. Carbon Fibers: Springer Series in Materials Science, Vol. 210, Springer Netherlands, 275 (2015). http://dx.doi.org/10.1007/978-94-0179478-7_8

[3] Kim SY, Kim SY, Lee S, Jo S, Im YH, Lee HS. Microwave plasma carbonization for the fabrication of polyacrylonitrile-based carbon fiber. Polymer, 56, 590 (2015). http://dx.doi.org/10.1016/j.polymer.2014.11.034.

[4] Rahaman MSA, Ismail AF, Mustafa A. A review of heat treatment 
on polyacrylonitrile fiber. Polym Degrad Stab, 92, 1421 (2007) http://dx.doi.org/10.1016/j.polymdegradstab.2007.03.023.

[5] Jo SM, Jang SY. Low cost carbon fiber. Polym Sci Technol, 21, 141 (2010).

[6] Frank E, Hermanutz F, Buchmeiser MR. Carbon fibers: precursors, manufacturing, and properties. Macromol Mater Eng, 297, 493 (2012). http://dx.doi.org/10.1002/mame.201100406

[7] Frank E, Steudle LM, Ingildeev D, Spörl JM, Buchmeiser MR. Carbon fibers: precursor systems, processing, structure, and properties. Angew Chem Int Ed, 53, 5262 (2014). http://dx.doi. org/10.1002/anie.201306129.

[8] Morgan P. Carbon Fibers and Their Composites, Taylor \& Francis, Boca Raton, FL (2005).

[9] Sedghi A, Farsani RE, Shokuhfar A. The effect of commercial polyacrylonitrile fibers characterizations on the produced carbon fibers properties. J Mater Process Technol, 198, 60 (2008). http:// dx.doi.org/10.1016/j.jmatprotec.2007.06.052.

[10] Leon y Leon CA, O'Brien R, McHugh JJ, Dasarathy H, Schimpf WC. Polyethylene and polypropylene as low cost carbon fiber (LCCF) precursors. Int SAMPE Tech Conf Series, 33, 1289 (2001).

[11] Leon y Leon CA, Schimpf WC, Hansen BC, Herren CW, Frame A, Heatherly PW. Low cost carbon fiber from non-acrylic based precursors: polyethylene. Int SAMPE Tech Conf Series, 34, 506 (2002).

[12] Dasarathy H, Hansen BC, Schimpf WC, Leon y Leon CA, Herren CW, Frame A, Heatherly PW. Low cost carbon fiber from radiated textile acrylics. Int SAMPE Tech Conf Series, 34, 520 (2002)

[13] Dasarathy H, Schimpf WC, Burleson T, Smith SB, Frame A, Heatherly PW. Low cost carbon fiber from chemically modified acrylics. Int SAMPE Tech Conf Series, 34, 531 (2002).

[14] Friedfeld B. Cost assessment of lignin-and PAN-based precursor for low-cost carbon fiber. Presentation for the Automotive Composites Consortium (17 January 2007).

[15] U.S. Department of Energy Office of FreedomCAR and Vehicle Technologies. Low-cost carbon fibers from renewable resources. FY 2004: Progress Report for Automotive Lightweighting Materials, U.S. Department of Energy Office of FreedomCAR and Vehicle Technologies, Washington, D.C., 125 (April 2005).

[16] Maradur SP, Kim CH, Kim SY, Kim BH, Kim WC, Yang KS. Preparation of carbon fibers from a lignin copolymer with polyacrylonitrile. Synth Met, 162, 453 (2012). http://dx.doi.org/10.1016/j. synthmet.2012.01.017.

[17] Shen Q, Zhang T, Zhang WX, Chen S, Mezgebe M. Lignin-based activated carbon fibers and controllable pore size and properties. J Appl Polym Sci, 121, 989 (2011). http://dx.doi.org/10.1002/ app.33701.

[18] Mohamad Ibrahim MN, Ahmed-Haras MR, Sipaut CS, AboulEnein HY, Mohamed AA. Preparation and characterization of a newly water soluble lignin graft copolymer from oil palm lignocellulosic waste. Carbohydr Polym, 80, 1102 (2010). http://dx.doi. org/10.1016/j.carbpol.2010.01.030

[19] Baker DA, Rials TG. Recent advances in low-cost carbon fiber manufacture from lignin. J Appl Polym Sci, 130, 713 (2013). http:// dx.doi.org/10.1002/app.39273

[20] Math F, Marianneau G. A new method for manufacturing carbonfibre microelectrodes. J Neurosci Methods, 52, 149 (1994).

[21] White TL, Paulauskas FL, Bigelow TS. System to continuously produce carbon fiber via microwave assisted plasma processing. US Patent 8,679,592 (2014)
[22] Kim SY, Kim SY, Choi J, Lee S, Jo SM, Joo J, Lee HS. Two step microwave plasma carbonization including low plasma power precarbonization for polyacrylonitrile based carbon fiber. Polymer, 69, 123 (2015). http://dx.doi.org/10.1016/j.polymer.2015.05.040.

[23] Yusof N, Ismail AF. Post spinning and pyrolysis processes of polyacrylonitrile (PAN)-based carbon fiber and activated carbon fiber: a review. J Anal Appl Pyrolysis, 93, 1 (2012). http://dx.doi. org/10.1016/j.jaap.2011.10.001.

[24] Wazir AH, Kakakhel L. Preparation and characterization of pitchbased carbon fibers. New Carbon Mater, 24, 83 (2009). http:// dx.doi.org/10.1016/S1872-5805(08)60039-6.

[25] Sauder C, Lamon J, Pailler R. The tensile behavior of carbon fibers at high temperatures up to $2400^{\circ} \mathrm{C}$. Carbon, $\mathbf{4 2}, 715$ (2004). http:// dx.doi.org/10.1016/j.carbon.2003.11.020.

[26] Roger B. Filamentary graphite and method for producing the same. US Patent 2,957,756 (1960)

[27] Alcañiz-Monge J, Cazorla-Amorós D, Linares-Solano A, Oya A, Sakamoto A, Hosm K. Preparation of general purpose carbon fibers from coal tar pitches with low softening point. Carbon, 35, 1079 (1997). http://dx.doi.org/10.1016/S0008-6223(97)00064-X.

[28] Mora E, Blanco C, Prada V, Santamaría R, Granda M, Menéndez R. A study of pitch-based precursors for general purpose carbon fibres. Carbon, 40, 2719 (2002). http://dx.doi.org/10.1016/S00086223(02)00185-9.

[29] Kim BJ, Eom Y, Kato O, Miyawaki J, Kim BC, Mochida I, Yoon SH. Preparation of carbon fibers with excellent mechanical properties from isotropic pitches. Carbon, 77, 747 (2014). http://dx.doi org/10.1016/j.carbon.2014.05.079.

[30] Huang X. Fabrication and properties of carbon fibers. Materials, 2, 2369 (2009). http://dx.doi.org/10.3390/ma2042369.

[31] Sutasinpromprae J, Jitjaicham S, Nithitanakul M, Meechaisue C, Supaphol P. Preparation and characterization of ultrafine electrospun polyacrylonitrile fibers and their subsequent pyrolysis to carbon fibers. Polym Int, 55, 825 (2006). http://dx.doi.org/10.1002/ pi.2040.

[32] Jie L, Wangxi Z. Structural changes during the thermal stabilization of modified and original polyacrylonitrile precursors. J Appl Polym Sci, 97, 2047 (2005). http://dx.doi.org/10.1002/app.21916.

[33] Kadla JF, Kubo S, Venditti RA, Gilbert RD, Compere AL, Griffith W. Lignin-based carbon fibers for composite fiber applications. Carbon, 40, 2913 (2002). http://dx.doi.org/10.1016/S00086223(02)00248-8

[34] Zhang WX, Wang YZ. Manufacture of carbon fibers from polyacrylonitrile precursors treated with $\mathrm{CoSO}_{4}$. J Appl Polym Sci, 85, 153 (2002). http://dx.doi.org/10.1002/app.10560.

[35] Paiva MC, Kotasthane P, Edie DD, Ogale AA. UV stabilization route for melt-processible PAN-based carbon fibers. Carbon, 41, 1399 (2003). http://dx.doi.org/10.1016/S0008-6223(03)00041-1.

[36] Bortner MJ, Bhanu V, McGrath JE, Baird DG. Shear rheological properties of acrylic copolymers and terpolymers suitable for potentially melt processable carbon fiber precursors. J Appl Polym Sci, 93, 2856 (2004). http://dx.doi.org/10.1002/app.20833.

[37] Naskar AK, Walker RA, Proulx S, Edie DD, Ogale AA. UV assisted stabilization routes for carbon fiber precursors produced from melt-processible polyacrylonitrile terpolymer. Carbon, 43, 1065 (2005). http://dx.doi.org/10.1016/j.carbon.2004.11.047.

[38] Odeshi AG, Mucha H, Wielage B. Manufacture and characterisation of a low cost carbon fibre reinforced $\mathrm{C} / \mathrm{SiC}$ dual matrix composite. Carbon, 44, 1994 (2006). http://dx.doi.org/10.1016/j.car- 
bon.2006.01.025.

[39] Warren CCD. Lightweighting composites and lower cost carbon fiber, Oak Ridge National Laboratory, U.S. Department of Energy (March 2013)

[40] Leitten C, Griffith W, Compere A, Shaffer J. High-volume, lowcost precursors for carbon fiber production. SAE Technical Paper 2002-01-1907 (2002). http://dx.doi.org/10.4271/2002-01-1907.

[41] Hyslop DK, Parent JS. Dynamics and yields of AOTEMPO-mediated polyolefin cross-linking. Polymer, 54, 84 (2013). http://dx.doi. org/10.1016/j.polymer.2012.11.013.

[42] Dumanlı AG, Windle AH. Carbon fibres from cellulosic precursors: a review. J Mater Sci, 47, 4236 (2012). http://dx.doi.org/10.1007/ s10853-011-6081-8.

[43] Edison TA. Manufacture of filaments for incandescent lamps. US Patent 470,922 (1892).

[44] Roger B, Cranch GE, Moyer RO, Watts WH. Process for manufacturing flexible carbonaceous textile material. US Patent 3,305,315 (1967).

[45] Roger B, Schalamon W. Process for producing carbon fibers having a high young's modulus of elasticity. US Patent 3,716,331 (1973).

[46] Shindo A. Studies on graphite fiber (Report No. 317), Government Industrial Research Institute, Osaka, Japan (1961).

[47] Calvo-Flores FG, Dobado JA. Lignin as renewable raw material. ChemSusChem, 3, 1227 (2010). http://dx.doi.org/10.1002/ cssc. 201000157.

[48] Kim KW, Lee HM, Kim BS, Hwang SH, Kwac LK, An KH, Kim BJ. Preparation and thermal properties of polyethylenebased carbonized fibers. Carbon Lett, 16, 62 (2015). http://dx.doi. org/10.5714/CL.2015.16.1.062.

[49] Baker FS. Low cost carbon fiber from renewable resources, Oak Ridge National Laboratory, U.S. Department of Energy (June 7-11 2010)

[50] Warren D, Naskar AK. Lower cost carbon fiber precursors (Project ID No. LM004), Oak Ridge National Laboratory (May 16 2012).

[51] Silverman J. Radiation processing: the industrial applications of radiation chemistry. J Chem Educ, 58, 168 (1981). http://dx.doi. org/10.1021/ed058p168.

[52] Uhniat M, Sudoł M, Kudła S. Stabilisation of LDPE cross-linked in the presence of peroxidesII. FTIR study of chemical changes taking place in the LDPE-dicumyl peroxide-Irganox 1081 system. Polym Degrad Stab, 71, 75 (2000). http://dx.doi.org/10.1016/ S0141-3910(00)00155-5.

[53] Narkis M, Tzur A, Vaxman A, Fritz HG. Some properties of silanegrafted moisture-crosslinked polyethylene. Polym Eng Sci, 25, 857 (1985). http://dx.doi.org/10.1002/pen.760251311.

[54] Zhang D, Sun Q. Structure and properties development during the conversion of polyethylene precursors to carbon fibers. J Appl Polym Sci, 62, 367 (1996). http://dx.doi.org/10.1002/(SICI)10974628(19961010)62:2<367::AID-APP11>3.0.CO;2-Z.

[55] Lewis G. Properties of crosslinked ultra-high-molecular-weight polyethylene. Biomaterials, 22, 371 (2001). http://dx.doi. org/10.1016/S0142-9612(00)00195-2.

[56] Alvarez VA, Perez CJ. Gamma irradiated LDPE in presence of oxygen. Part I. Non-isothermal crystallization. Thermochim Acta, 570, 64 (2013). http://dx.doi.org/10.1016/j.tca.2013.07.026.

[57] Cardoso ECL, Scagliusi SR, Parra DF, Lugão AB. Gamma-irradiated cross-linked LDPE foams: characteristics and properties. Radiat Phys Chem, 84, 170 (2013). http://dx.doi.org/10.1016/j. radphyschem.2012.06.023

[58] Murray KA, Kennedy JE, McEvoy B, Vrain O, Ryan D, Higginbotham CL. The effects of high energy electron beam irradiation on the thermal and structural properties of low density polyethylene. Radiat Phys Chem, 81, 962 (2012). http://dx.doi.org/10.1016/j.radphyschem.2011.09.011.

[59] Khonakdar HA, Jafari SH, Wagenknecht U, Jehnichen D. Effect of electron-irradiation on cross-link density and crystalline structure of low- and high-density polyethylene. Radiat Phys Chem, 75, 78 (2006). http://dx.doi.org/10.1016/j.radphyschem.2005.05.014.

[60] Turos A, Jagielski J, Piątkowska A, Bieliński D, Ślusarski L, Madi NK. Ion beam modification of surface properties of polyethylene. Vacuum, 70, 201 (2003). http://dx.doi.org/10.1016/S0042 207X(02)00643-7.

[61] Sahre K, Eichhorn KJ, Simon F, Pleul D, Janke A, Gerlach G. Characterization of ion-beam modified polyimide layers. Surf Coat Technol, 139, 257 (2001). http://dx.doi.org/10.1016/S02578972(01)01013-1.

[62] Lee EH, Rao GR, Mansur LK. LET effect on cross-linking and scission mechanisms of PMMA during irradiation. Radiat Phys Chem, 55, 293 (1999). http://dx.doi.org/10.1016/S0969-806X(99)00184$\mathrm{X}$

[63] Nilsson S, Hjertberg T, Smedberg A. Structural effects on thermal properties and morphology in XLPE. Eur Polym J, 46, 1759 (2010). http://dx.doi.org/10.1016/j.eurpolymj.2010.05.003.

[64] Rouif S. Radiation cross-linked plastics: a versatile material solution for packaging, automotive, electrotechnic and electronics. Radiat Phys Chem, 71, 527 (2004). http://dx.doi.org/10.1016/j.radphyschem.2004.03.050.

[65] Rizzo P, Baione F, Guerra G, Martinotto L, Albizzati E. Polyethylene unit cell and crystallinity variations as a consequence of different cross-linking processes. Macromolecules, 34, 5175 (2001). http://dx.doi.org/10.1021/ma010121z.

[66] Smedberg A, Hjertberg T, Gustafsson B. Effect of molecular structure and topology on network formation in peroxide crosslinked polyethylene. Polymer, 44, 3395 (2003). http://dx.doi.org/10.1016/ S0032-3861(03)00179-4

[67] Sajkiewicz P, Phillips PJ. Peroxide crosslinking of linear lowdensity polyethylenes with homogeneous distribution of short chain branching. J Polym Sci A, 33, 853 (1995). http://dx.doi. org/10.1002/pola.1995.080330512.

[68] Celina M, George GA. Characterisation and degradation studies of peroxide and silane crosslinked polyethylene. Polym Degrad Stab, 48, 297 (1995).

[69] Cameron R, Lien K, Lorigan P. Advances in silane cross-linkable polyethylene. Wire J Int, 23, 56 (1990).

[70] Fabris FW, Stedile FC, Mauler RS, Nachtigall SMB. Free radical modification of LDPE with vinyltriethoxysilane. Eur Polym J, 40, 1119 (2004). http://dx.doi.org/10.1016/j.eurpolymj.2004.01.008.

[71] Marcilla A, Ruiz-Femenia R, Hernández J, García-Quesada JC Thermal and catalytic pyrolysis of crosslinked polyethylene. J Anal Appl Pyrolysis, 76, 254 (2006). http://dx.doi.org/10.1016/j. jaap.2005.12.004.

[72] Yu S, Park C, Hong SM, Koo CM. Thermal conduction behaviors of chemically cross-linked high-density polyethylenes. Thermochim Acta, 583, 67 (2014). http://dx.doi.org/10.1016/j.tca.2014.03.018.

[73] Wu H, Liang M, Lu C. Non-isothermal crystallization kinetics of peroxide-crosslinked polyethylene: Effect of solid state mechanochemical milling. Thermochim Acta, 545, 148 (2012). http:// 
dx.doi.org/10.1016/j.tca.2012.07.008.

[74] Harper CA, Petrie EM. Plastics Materials and Processes: A Concise Encyclopedia, Wiley-Interscience, Hoboken, NJ (2003).

[75] Akutsu S, Isaka T, Ishioka M. Process for producing electric conductors coated with crosslinked polyethylene resin. US Patent 4,297,310 (1981).

[76] Rodríguez-Fernández OS, Gilbert M. Aminosilane grafting of plasticized poly(vinyl chloride) I. Extent and rate of crosslinking. J Appl Polym Sci, 66, 2111 (1997). http://dx.doi.org/10.1002/ (SICI) 1097-4628(19971219)66:11<2111::AID-APP7>3.0.CO;2$\mathrm{K}$.

[77] Schmid E. Method for the manufacture of crosslinked polyamide articles. US Patent 5,055,249 (1991).

[78] Cartasegna S. Silane-grafted/moisture-curable ethylene: propylene elastomers for the cable industry. Rubber Chem Technol, 59, 722 (1986). http://dx.doi.org/10.5254/1.3538230.

[79] Gale GM. Silane compounds in hot-water pipe and cable technology. Appl Organomet Chem, 2, 17 (1988). http://dx.doi.org/10.1002/ aoc.590020104.

[80] Smedberg A, Hjertberg T, Gustafsson B. Crosslinking reactions in an unsaturated low density polyethylene. Polymer, 38, 4127 (1997). http://dx.doi.org/10.1016/S0032-3861(96)00994-9.

[81] Yussuf AA, Kosior E, Alban L. Silane grafting and crosslinking of metallocene-catalysed LLDPE and LDPE. Malays Polym J, 2, 58 (2007).

[82] Morshedian J, Hoseinpour PM. Polyethylene cross-linking by twostep silane method: a review. Iran Polym J, 18, 103 (2009).

[83] Oliveira GL, Costa MF. Optimization of process conditions, characterization and mechanical properties of silane crosslinked highdensity polyethylene. Mater Sci Eng, A, 527, 4593 (2010). http:// dx.doi.org/10.1016/j.msea.2010.03.102.

[84] Sirisinha K, Boonkongkaew M, Kositchaiyong S. The effect of silane carriers on silane grafting of high-density polyethylene and properties of crosslinked products. Polym Test, 29, 958 (2010). http://dx.doi.org/10.1016/j.polymertesting.2010.08.004.

[85] Sirisinha K, Chimdist S. Comparison of techniques for determining crosslinking in silane-water crosslinked materials. Polym Test, 25, 518 (2006). http://dx.doi.org/10.1016/j.polymertesting.2006.01.015.

[86] Ihata J. Formation and reaction of polyenesulfonic acid. I. Reaction of polyethylene films with $\mathrm{SO}_{3}$. J Polym Sci A, 26, 167 (1988). http://dx.doi.org/10.1002/pola.1988.080260116.

[87] Younker JM, Saito T, Hunt MA, Naskar AK, Beste A. Pyrolysis pathways of sulfonated polyethylene, an alternative carbon fiber precursor. J Am Chem Soc, 135, 6130 (2013). http://dx.doi. org/10.1021/ja3121845.

[88] Werkema EL, Castro L, Maron L, Eisenstein O, Andersen RA. Selectivity in the $\mathrm{C}-\mathrm{H}$ activation reaction of $\mathrm{CH}_{3} \mathrm{OSO}_{2} \mathrm{CH}_{3}$ with $\left[1,2,4-\left(\mathrm{Me}_{3} \mathrm{C}\right)_{3} \mathrm{C}_{5} \mathrm{H}_{2}\right]_{2} \mathrm{CeH}$ or $\left[1,2,4-\left(\mathrm{Me}_{3} \mathrm{C}\right)_{3} \mathrm{C}_{5} \mathrm{H}_{2}\right]\left[1,2-\left(\mathrm{Me}_{3} \mathrm{C}\right)_{2}-4-\right.$ $\left.\left(\mathrm{Me}_{2} \mathrm{CCH}_{2}\right)_{5} \mathrm{H}_{2}\right] \mathrm{Ce}$ : to choose or not to choose. Organometallics, 31, 870 (2012). http://dx.doi.org/10.1021/om200842t.

[89] Mansfield E, Kar A, Quinn TP, Hooker SA. Quartz crystal microbalances for microscale thermogravimetric analysis. Anal Chem, 82, 9977 (2010). http://dx.doi.org/10.1021/ac102030z.

[90] Flynn JH, Wall LA. A quick, direct method for the determination of activation energy from thermogravimetric data. J Polym Sci B, 4, 323 (1966). http://dx.doi.org/10.1002/pol.1966.110040504.

[91] Smith M, March J. March's Advanced Organic Chemistry: Reactions, Mechanisms, and Structure. 5th ed., Wiley, New York, NY,
1298 (2001).

[92] Cubbage JW, Vos BW, Jenks WS. Ei elimination: an unprecedented facet of sulfone chemistry. J Am Chem Soc, 122, 4968 (2000). http://dx.doi.org/10.1021/ja994150p.

[93] Cubbage JW, Guo Y, McCulla RD, Jenks WS. Thermolysis of alkyl sulfoxides and derivatives: a comparison of experiment and theory. J Org Chem, 66, 8722 (2001). http://dx.doi.org/10.1021/ jo0160625.

[94] Claes L, François JP, Deleuze MS. From sulfoxide precursors to model oligomers of conducting polymers. J Am Chem Soc, 124, 7563 (2002). http://dx.doi.org/10.1021/ja012700p.

[95] Claes L, François JP, Deleuze MS. Theoretical study of the conversion of sulfonyl precursors into chains of poly(p-phenylene vinylene). J Am Chem Soc, 125, 7129 (2003). http://dx.doi.org/10.1021/ ja021295e.

[96] Zhao YL, Jones WH, Monnat F, Wudl F, Houk KN. Mechanisms of thermal decompositions of polysulfones: a DFT and CBSQB3 study. Macromolecules, 38, 10279 (2005). http://dx.doi. org/10.1021/ma051503y.

[97] Zhao Y, Truhlar D. The M06 suite of density functionals for main group thermochemistry, thermochemical kinetics, noncovalent interactions, excited states, and transition elements: two new functionals and systematic testing of four M06-class functionals and 12 other functionals. Theor Chem Acc, 120, 215 (2008). http://dx.doi. org/10.1007/s00214-007-0310-x

[98] Zhao Y, Schultz NE, Truhlar DG. Design of density functionals by combining the method of constraint satisfaction with parametrization for thermochemistry, thermochemical kinetics, and noncovalent interactions. J Chem Theory Comput, 2, 364 (2006). http:// dx.doi.org/10.1021/ct0502763.

[99] Denis PA. Basis set requirements for sulfur compounds in density functional theory: a comparison between correlation-consistent, polarized-consistent, and pople-type basis sets. J Chem Theory Comput, 1, 900 (2005). http://dx.doi.org/10.1021/ct0500702.

[100] Korang J, Grither WR, McCulla RD. Comparison of experimental and computationally predicted sulfoxide bond dissociation enthalpies. J Phys Chem A, 115, 2859 (2011). http://dx.doi org/10.1021/jp1109465.

[101] Stoffregen SA, McCulla RD, Wilson R, Cercone S, Miller J, Jenks WS. Sulfur and selenium ylide bond enthalpies. J Org Chem, 72, 8235 (2007). http://dx.doi.org/10.1021/jo0711438.

[102] McCulla RD, Jenks WS. Effects of Si substitution on the Ei reaction of alkyl sulfoxides. J Org Chem, 68, 7871 (2003). http:/ dx.doi.org/10.1021/jo034690b.

[103] Wheeler SE, Houk KN. Integration grid errors for meta-GGApredicted reaction energies: origin of grid errors for the M06 suite of functionals. J Chem Theory Comput, 6, 395 (2010). http:// dx.doi.org/10.1021/ct900639j.

[104] Holbrook KA, Pilling MJ, Robertson SH, Robinson PJ. Unimolecular Reactions. 2nd ed., Wiley, New York, NY (1996).

[105] Henriksen NE, Hansen FY. Theories of Molecular Reaction Dynamics: The Microscopic Foundation of Chemical Kinetics, Oxford University Press, New York, NY (2008)

[106] Beste A, Buchanan AC, Britt PF, Hathorn BC, Harrison RJ. Kinetic analysis of the pyrolysis of phenethyl phenyl ether: computational prediction of $\alpha / \beta$-selectivities. J Phys Chem A, 111, 12118 (2007). http://dx.doi.org/10.1021/jp075861+.

[107] McCulla RD, Cubbage JW, Jenks WS. Pyrolytic elimination reactions of sulfinate and sulfonate esters. J Phys Org Chem, 15, 71 
(2002). http://dx.doi.org/10.1002/poc.464.

[108] Sandia National Laboratories, U.S. Department of Energy. Crossing the Mesoscale No-man's Land via Parallel Kinetic Monte Carlo. U.S. Department of Energy, Washington, D.C. (2009).

[109] R Development Core Team. R: A Language and Environment for Statistical Computing, R Foundation for Statistical Computing, Vienna, Austria (2008).
[110] Postema AR, De Groot H, Pennings AJ. Amorphous carbon fibres from linear low density polyethylene. J Mater Sci, 25, 4216 (1990). http://dx.doi.org/10.1007/BF00581075.

[111] Penning JP, Lagcher R, Pennings AJ. The effect of diameter on the mechanical properties of amorphous carbon fibres from linear low density polyethylene. Polym Bull, 25, 405 (1991). http:// dx.doi.org/10.1007/BF00316913. 